Review

\title{
Modified Electrodes Used for Electrochemical Detection of Metal Ions in Environmental Analysis
}

\section{Gregory March ${ }^{1, \dagger}$, Tuan Dung Nguyen ${ }^{2, \dagger}$ and Benoit Piro ${ }^{3, \dagger, *}$}

1 Klearia, route de Nozay, Marcoussis 91460, France; E-Mail: gregory.march@free.fr

2 Institute for Tropical Technology, Vietnam Academy of Science and Technology, 18 Hoang Quoc Viet, Cau Giay District, Hanoi, Vietnam; E-Mail: ndung@ itt.vast.vn

3 Chemistry Department, University Paris Diderot, Sorbonne Paris Cité, ITODYS, UMR 7086 CNRS, 15 rue J-A de Baïf, 75205 Paris Cedex 13, France

$\dagger$ These authors contributed equally to this work.

* Author to whom correspondence should be addressed; E-Mail: piro@ univ-paris-diderot.fr; Tel.: +33-1-5727-7224.

Academic Editor: Andrew M. Shaw

Received: 30 December 2014 / Accepted: 22 April 2015 / Published: 29 April 2015

\begin{abstract}
Heavy metal pollution is one of the most serious environmental problems, and regulations are becoming stricter. Many efforts have been made to develop sensors for monitoring heavy metals in the environment. This review aims at presenting the different label-free strategies used to develop electrochemical sensors for the detection of heavy metals such as lead, cadmium, mercury, arsenic etc. The first part of this review will be dedicated to stripping voltammetry techniques, on unmodified electrodes (mercury, bismuth or noble metals in the bulk form), or electrodes modified at their surface by nanoparticles, nanostructures (CNT, graphene) or other innovative materials such as boron-doped diamond. The second part will be dedicated to chemically modified electrodes especially those with conducting polymers. The last part of this review will focus on bio-modified electrodes. Special attention will be paid to strategies using biomolecules (DNA, peptide or proteins), enzymes or whole cells.
\end{abstract}

Keywords: heavy metals; electrochemical sensors; stripping voltammetry; conducting polymers; DNA; enzymes; whole cells 


\section{Introduction}

Heavy metals (HMs) are persistent in the environment (waters and soils), which means that they cannot be degraded. HMs mainly come from anthropic activities such as mining, smelting, or different kinds of wastes. Keep in mind that, among HMs, although some are necessary for life (iron, selenium, cobalt, copper, manganese, molybdenum, zinc), unfortunately, many others are toxic. For example, mercury $(\mathrm{Hg})$ enters the environment through not only coal burning but also through mining or industrial wastes, and is known to cause damage mainly to the nervous system; Lead ( $\mathrm{Pb}$ ) comes from automobile exhausts, old paints, mining wastes, incinerator ash or water from lead pipes and is also known to causes damage to the nervous system; Cadmium $(\mathrm{Cd})$, which causes kidney diseases, comes from the electroplating and mining industries; lastly, arsenic (As) comes from herbicides or, again, from the mining industry and causes damage to skin, eyes, and liver. Other major heavy metals are chromium, nickel, tin and thallium. For sanitary reasons, it has become necessary to detect and quantify HMs in soils or in waters. For example, French regulations set mercury contents in drinking water at $1 \mu \mathrm{g} \cdot \mathrm{L}^{-1}$, silver or lead at $10 \mu \mathrm{g} \cdot \mathrm{L}^{-1}$ and arsenic at $50 \mu \mathrm{g} \cdot \mathrm{L}^{-1}$.

Traditional analytical methods are atomic absorption or emission spectroscopies (AAS, AES [1,2]), inductively coupled plasma mass spectrometry (ICP-MS [3]) or cold vapor atomic fluorescence spectrometry (CVAFS [4]). They are extremely sensitive but are however expensive and require laborious pre-treatment processes [5]. Therefore, in some cases, these methods may be replaced by more easy-to-use and inexpensive ones such as sensors, which may be based on either optical transduction (e.g., photonic crystal sensors [6-9]) or on electrochemical transduction (ion-selective electrodes, polarography, potentiometry, amperometry, conductimetry...) on which the review will more specifically focus. Other transduction methods have been extensively reviewed elsewhere.

Heavy metals are generally present under their cationic form $\left(\mathrm{Hg}^{2+}, \mathrm{Pb}^{2+}, \mathrm{Cd}^{2+} \ldots\right)$, therefore, they can be electroreduced to the corresponding metal at an electrode; this corresponds with a preconcentration step, because a large amount of metal can be deposited on the electrode even if the cation concentration is low, providing that the deposition (electroreduction) time is sufficiently long. In a second step, an anodic potential scan is applied, so that the metal is oxidized back to the corresponding cation. This electrochemical reaction is extremely fast, giving a strong current (proportional to the quantity of metal ion initially present in the medium) and providing high sensitivity; in addition, each metal is oxidized at a particular potential, which provides specificity. This method is called Anodic Stripping Voltammetry (ASV) and is extremely pertinent for HMs quantification. The first part of this review will be dedicated to this technique used on unmodified electrodes (mercury, bismuth or noble metals in the bulk form), or electrodes modified at their surface by nanoparticles, nanostructures (CNT, graphene) or other innovative materials such as boron-doped diamond.

Another way to functionalize electrodes is to use conducting polymers (polypyrrole, polythiophene, polyaniline, polynapthalene, etc.). One main reason for the interest in conducting polymers (CPs) is that small perturbations at their surface or in their bulk can generate strong changes in their electroactivity, which can be probed by amperometry or potentiometry. Another interest of CPs, beyond the simplicity they offer in modifying a conducting surface, is that they are easy to functionalize with additional chemical functions. The easiest way is to dope CPs with doping ions carrying the required function. The 
other way is to chemically modify the backbone of the CPs with the desired function. Additionally, it has been shown that some CPs are biocompatible, and therefore are convenient for binding biomolecules.

Biomolecules such as DNA, peptides or proteins have been reported to selectively bind HM ions. This allows for selective preconcentration of ions at an electrode surface before stripping voltammetry, therefore avoiding interferences between metals. Lastly, beyond the use of simple biomolecules, enzymes (generally phosphatase or urease) have been also employed for the detection of HMs, which interact with their active site and lower their activity (this phenomenon is called enzyme inhibition). However, isolated enzymes immobilized on electrodes are often unstable; this is why whole cells such as microalgae or other micro-organisms, containing themselves active enzymes, have attracted much interest. All these items will be detailed in this review.

\section{Generalities on Stripping Voltammetry}

Stripping voltammetry comprises a group of various techniques including Anodic Stripping Voltammetry, Cathodic Stripping Voltammetry (CSV) and Adsorptive Stripping Voltammetry (AdSV). It is an ultrasensitive detection technique based on electrochemical measurements similar to polarography. Stripping voltammetry is a two-step technique that allows simultaneous detection of various inorganic and organic species in the sub-nanomolar range. The first step consists of the electrolytic deposition of a chemical species onto an inert electrode surface at a constant potential. This preconcentration step explains the remarkable sensitivity of the technique. It can involve either an anodic or cathodic process. However, the most common use of stripping voltammetry involves a cathodic process for deposition in which the metal ionic species are reduced from the solution to the electrode surface. The second step consists of the application of a voltage scan to the electrode. At a specific potential, it causes the stripping of a specific species accumulated onto the electrode surface as amalgam or thin films, into the solution. The resulting faradic current is proportional to the concentration of the chemical species (Figure 1).

Pre-concentration Stripping

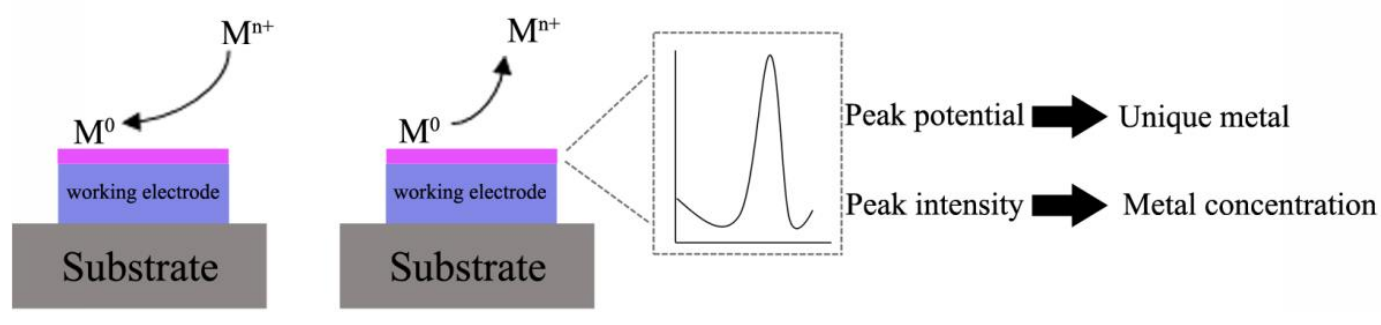

Figure 1. Anodic Stripping Voltammetry (ASV) principle.

In AdSV, conversely to ASV, the preconcentration step of the metal ions at the surface of the electrode is made by a non-electrochemical process, in the form of complexes. Notably, Ni and Co were quantified by AdSV after complexation with dimethylglyoxime [10], Cr after complexation with cupferron [11] and $\mathrm{Al}$ after complexation with cupferron [12] or Eriochrome blue black R [13]. In analytical practice, stripping voltammograms are recorded in the Differential Pulse (DP) or Square Wave (SW) modes, which are generally more sensitive than normal scan mode. Table 1 addresses a list of HMs detectable by these three different stripping voltammetries. 
Table 1. List of heavy metals that can be detected with stripping voltammetry techniques.

\begin{tabular}{lcc}
\hline & Metals that can be determined by Anodic Stripping Voltammetry \\
Antimony & Gallium & Mercury \\
Arsenic & Germanium & Silver \\
Bismuth & Manganese & Thallium \\
Cadmium & Indium & Tin \\
Copper & Lead & Zinc \\
\hline & Species that can be determined by Cathodic Stripping Voltammetry \\
Arsenic & Iodide & Mercaptans \\
Chloride & Selenium & Thiocyanate \\
Bromide & Sulfide & Thio compounds \\
\hline & Metals that can be determined by Adsorptive Stripping Voltammetry \\
Aluminum & Nickel & Uranium \\
Cobalt & Chromium & Iron \\
\hline
\end{tabular}

\section{Electrode Materials}

\subsection{Mercury Electrodes}

The performance of ASV is strongly influenced by the material of the working electrode. Traditionally, hanging mercury drop electrodes (HMDE) have been used, mainly because clean surfaces can be easily regenerated with a new mercury drop. Moreover, the potential window where mercury stays electro-inactive is very large, so that very electronegative metals can be detected. Despite being long known as an electrode, it is still used and upgraded. For example, Adam et al. [14] have detected $\mathrm{Cd}^{2+}$ and $\mathrm{Zn}^{2+}$ with a phytochelatin-modified HMDE using AdSV. However, HMDE present several drawbacks: metallic ions such as $\mathrm{Hg}$, $\mathrm{Au}$ and $\mathrm{Ag}$ cannot be measured and the use of mercury electrodes is now severely restricted due to obvious toxicity considerations. Mercury thin film electrodes (MFEs) could be an alternative as less mercury is necessary. Nevertheless, the development of mercury-free analytical systems is becoming inevitable.

\subsection{Gold and Silver Electrodes}

Kirowa-Eisner et al. used gold [15,16] and silver [17-19] electrodes to detect cadmium, lead and copper. They showed that gold is unsuitable for mixtures of lead and cadmium because of overlapping of the two stripping peaks. Silver exhibits excellent characteristics for lead and cadmium detection: high repeatability and long-term stability without the need of any pretreatment, with limits of detection (LoD) in the $\mathrm{nM}$ range. The sensitivity can be further improved by using advanced procedures or electrode surfaces. For example, Compton's group has detected arsenic(III) with a LoD of 1 ppb on gold [20] and silver [21] electrodes using ASV assisted with ultrasound. Rahman et al. [22] have reached a LoD of 0.28 ppb using Au(111)-like polycrystalline electrodes. They have shown that trace level of As(III) could be detected in tap water even in the presence of $\mathrm{Cu}$. Total inorganic arsenic determination was achieved using differential pulse ASV (DPASV) in real samples at a gold-coated diamond thin film electrode with a LoD of ca. $20 \mathrm{ppb}$ [23]. Note that Compton et al. have also shown that gold electrodes are highly sensitive for the detection of chromium(VI) even with cyclic voltammetry, with a LoD of 228 ppb and 
have proven superior performances compared to glassy carbon and bore doped diamond [24]. Using gold film-modified carbon composite electrode, Kachoosangi and Compton achieved a LoD of 4.4 ppb for chromium(VI) [25].

\subsection{Gold Nanoparticles-Modified Electrodes}

Nanostructured gold electrodes have been shown to improve LoD. In particular, several papers described the successful use of gold nanoparticles-modified electrodes. Compton's group developed a gold-NPs modified glassy carbon electrode for arsenic(III) detection, with a LoD of $0.0096 \mathrm{ppb}$ using LSV [26]. Jena et al. developed a highly sensitive platform based on gold nanoelectrodes ensembles (GNEEs). GNEEs were grown by colloidal approach on thiol-functionalized 3D silicate network preassembled on polycrystalline gold electrode (Figure 2). Using square wave anodic stripping voltammetry (SWASV), they achieved simultaneous detection of arsenic(III) and $\mathrm{Hg}$ (II) in presence of $\mathrm{Cu}(\mathrm{II})$ with a LoD of $0.02 \mathrm{ppb}$ [27]. Detection of $\mathrm{Cr}(\mathrm{VI})$ was also achieved with the same platform with a LoD of $0.1 \mathrm{ppb}$ [28]. Mordegan et al. developed GNEEs using a polycarbonate membrane as template for a better control of the nanoelectrodes density. A LoD of 5 ppt was achieved for arsenic detection [29].

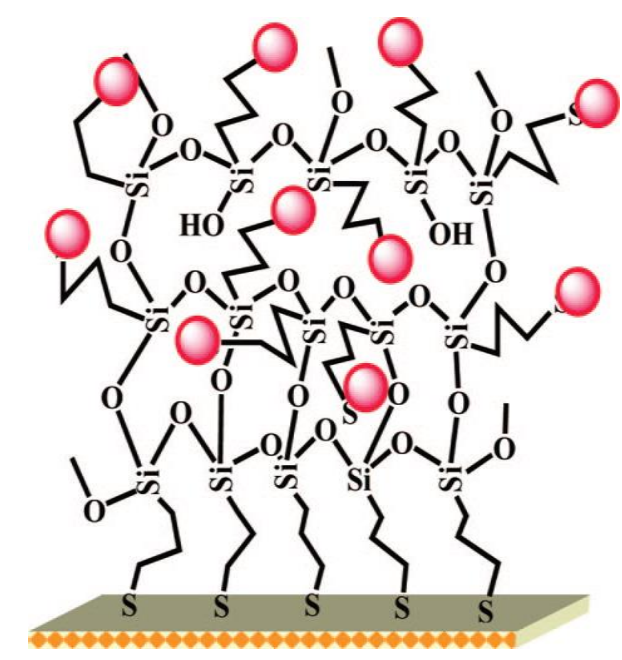

Figure 2. Schematic illustrations of gold nanoelectrode ensembles (GNEEs) dedicated to the detection of arsenic using a colloidal chemical approach on thiol-functionalized 3D silicate network preassembled on polycrystalline gold electrode. Reprinted with permission from [27]. Copyright 2008 American Chemical Society.

\subsection{Bismuth Film Electrodes}

In 2000, bismuth-film electrodes (BFEs) were introduced as an alternative to mercury film electrodes (MFEs) [30]. BFEs are prepared by plating thin bismuth films on suitable electrode materials. The main advantages of the BFEs are that they are environmentally friendly, since the toxicity of bismuth and bismuth ions is negligible, and their analytical properties are comparable to those of MFEs. Bismuth can be plated on the same substrate as mercury: glassy carbon [31], screen-printed carbon ink [32,33] and gold [34] have been successfully used. It has also been shown that BFEs offer a better separation between intermetallic compounds than MFEs, e.g., $\mathrm{Cd}^{2+}$ and $\mathrm{Pb}^{2+}$, even if a large excess of $\mathrm{Cu}^{2+}$ is present $[35,36]$. 
The method for electroplating the electrode surface with bismuth is critical to obtaining satisfactory performances. Three methods exist to realize a bismuth deposit [37]. The first method, ex situ plating, consists of electroplating the bismuth film before transferring the electrode into the sample solution for analysis. The plating conditions are variable but acidic media are recommended as bismuth ions are easily hydrolyzed as high $\mathrm{pH}$. Plating solutions containing $5-200 \mathrm{mg} \cdot \mathrm{L}^{-1} \mathrm{Bi}$ (III) are used with a deposition potential comprised between -0.5 and $-1.2 \mathrm{~V}$ and deposition time of 1-8 min under conditions of forced convection (electrode rotation or convection). The second method, in situ plating, consists of adding directly $\mathrm{Bi}(\mathrm{III})$ ions in the concentration range $400-1000 \mathrm{mg} \cdot \mathrm{L}^{-1}$ into the sample solution. The bismuth film is deposited onto the electrode surface during the analysis. The main restriction of this method is the $\mathrm{pH}$ which must be fairly acidic, for the reason given above. The last method is essentially confined to carbon-paste electrodes. It is based on modifying the bulk of an electrode with bismuth compounds such as $\mathrm{Bi}_{2} \mathrm{O}_{3}$.

Ex situ plating is more versatile as electroplating conditions are independent of analysis conditions but more complex and time consuming than in situ plating. Moreover, BFEs prepared with the ex situ method can be reused: the surface of the electrode is reactivated after each analysis by polarization at an adequate potential, more negative than the oxidation potential of bismuth but more positive than the oxidation stripping potential of metal ions. In practice, a short cleaning step of $10-30 \mathrm{~s}$ at $-0.35 \mathrm{~V}$ to $-0.40 \mathrm{~V}$ in stirred solution is sufficient. For the in situ method, the bismuth film is stripped after each analysis at a potential more positive than the oxidation potential of bismuth, typically in the range $0.0 \mathrm{~V}$ to $+0.3 \mathrm{~V}$, during a few tens of seconds, then a new bismuth film is re-plated.

The main disadvantage of BFEs compared to MFEs is their lower potential window, particularly a more negative anodic limit due to the fact that bismuth is more easily oxidized than mercury. However, the cathodic limit potential is almost the same as MFEs. The $\mathrm{pH}$ of the sample solution strongly affects the useful potential window of BFEs. As expected, the most cathodic potential limit was achieved in basic media whereas the most anodic potential limit was achieved in very acidic media. Table 2 shows potential ranges of BFEs at different $\mathrm{pH}$ values [37], and Figure 3 shows an example for simultaneous $\mathrm{Pb}^{2+}, \mathrm{Zn}^{2+}$ and $\mathrm{Cd}^{2+}$ determination.

Table 2. Potential ranges of BFEs plated on carbon paste at different $\mathrm{pH}$ values (numerical values taken from [37]).

\begin{tabular}{ccccc}
\hline Medium & pH & Anodic Limit (V) & Cathodic Limit (V) & Potential Window (V) \\
\hline $\mathbf{0 . 1 M ~ H C l O}_{4}$ & 1.00 & -0.05 & -1.05 & 1.10 \\
$\mathbf{0 . 2 M}$ acetate buffer & 4.24 & -0.25 & -1.25 & 1.00 \\
0.1 M NaOH & 12.17 & -0.55 & -1.55 & 1.00 \\
\hline
\end{tabular}

Nunes et al. [38] studied the influence of electrodeposition conditions on the electroanalytical performances of bismuth films deposited on copper electrodes. They showed that the morphology of the film was of great importance, the most homogeneous films giving better analytical performances for lead detection. Evaporated bismuth was also used, which provided favorable reproducibility and sensitivity for heavy metal detection $[39,40]$ and could be easily shaped into arrays $[41,42]$ or integrated into microfluidic devices [43]. 


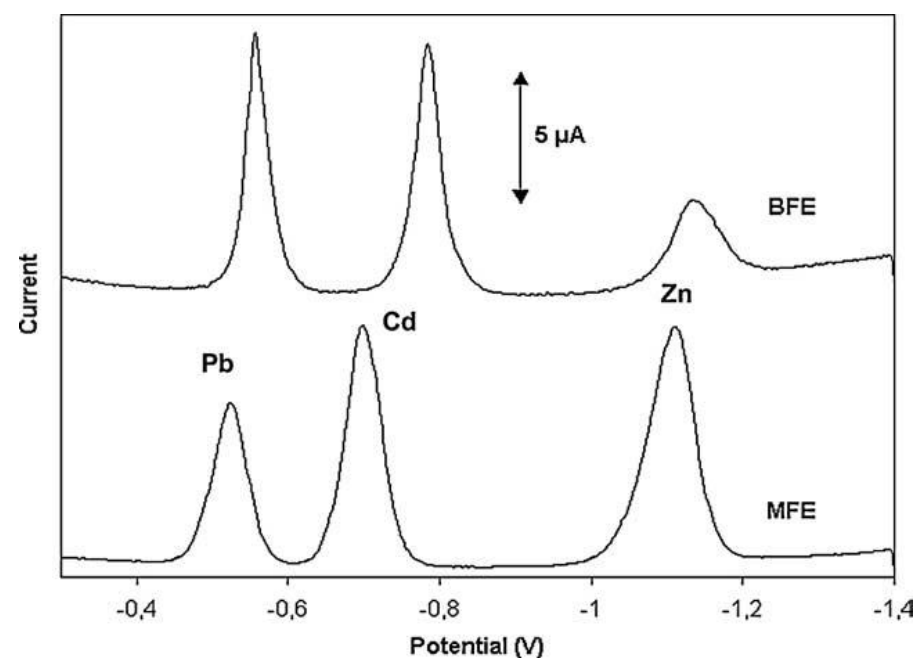

Figure 3. Comparative voltammograms of a solution containing $20 \mathrm{ppb}$ each of $\mathrm{Pb}(\mathrm{II})$, $\mathrm{Cd}(\mathrm{II})$ and $\mathrm{Zn}$ (II) in $0.1 \mathrm{M}$ acetate buffer ( $\mathrm{pH}$ 4.5) on in situ plated BFE and MFE on a glassy carbon support. Reprinted from [37] with permission from Elsevier.

\subsection{Antimony Film Electrodes}

The use of antimony film electrodes (SbFEs) for electrochemical stripping analysis was first reported by Hocevar et al. in 2007 [44] (Figure 4) although the fact that the use of antimony as electrode material was known since 1923 for $\mathrm{pH}$ measurements [45]. As for bismuth, two methods of plating are commonly used: ex situ and in situ plating. SbFEs exhibit a very similar electrochemical stripping behavior to BFEs, with almost the same sensitivity towards $\mathrm{Pb}$ (II) and a slightly higher sensitivity towards $\mathrm{Cd}(\mathrm{II})$. With respect to the MFEs, both BFEs and SbFEs provide an improved sensitivity towards cadmium whereas it is the opposite for lead. Also, compared to BFEs, SbFEs provides a more favorable hydrogen evolution which is comparable to MFEs. SbFEs were notably used for detection of $\mathrm{Pb}, \mathrm{Cd}$ and $\mathrm{Zn}$ in tap and river water [46] and for the detection of Ni using complexation with dimethylglyoxime $[47,48]$.

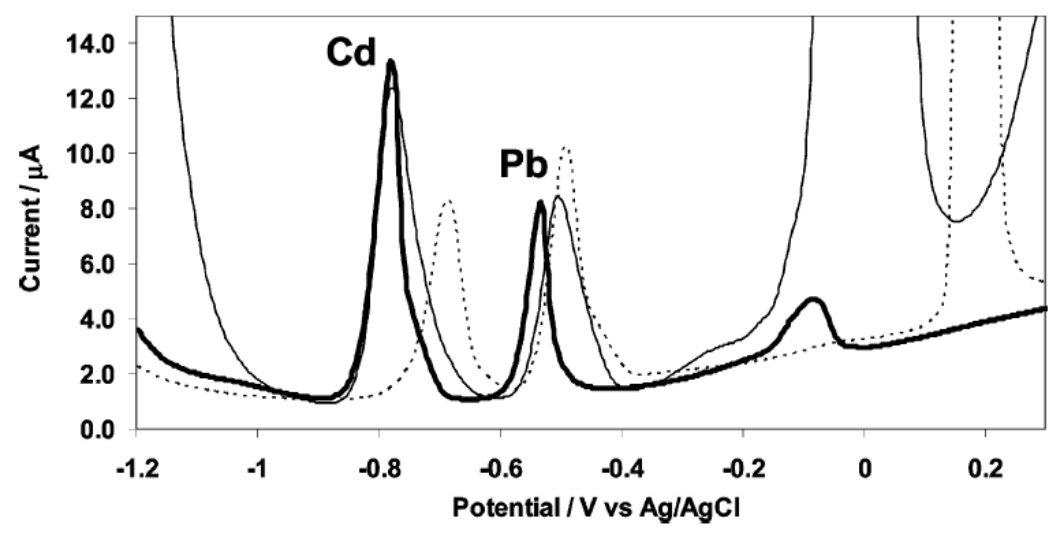

Figure 4. Anodic stripping voltammograms of cadmium(II) and lead(II) at in situ prepared antimony film (thick line), bismuth film (thin line) and mercury film (dashed line) electrodes. Solution: $0.01 \mathrm{M}$ hydrochloric acid ( $\mathrm{pH}$ 2) containing $50 \mathrm{ppb}$ cadmium(II) and lead(II) together with $1 \mathrm{mg} \cdot \mathrm{L}^{-1}$ antimony(III), bismuth(III), or mercury(II). Reprinted with permission from [44]. Copyright 2007 American Chemical Society. 


\subsection{Bore Doped Diamond (BDD)}

Conductive diamond films are a new type of material which are used more and more for electroanalytical purpose. Indeed, these materials present remarkable properties among carbon materials: (i) a low and stable background current; (ii) relatively high electronic transfer rate; (iii) a low molecular adsorption; (iv) resistance to corrosion; and (v) optical transparency. Usually, diamond films are deposited on conductive substrates such as highly doped silicon wafer, molybdenum, tungsten or titanium using plasma-wave assisted chemical vapor deposition (PACVD) or hot filament.

At the pristine state, diamond is one the best known electrical isolators. In order to have an appropriate conductivity to be used as an electrode for electrochemical measurements $\left(>10 \mathrm{~S} \cdot \mathrm{cm}^{-1}\right)$, diamond needs to be doped. The most frequently used dopant is boron and such electrodes are called boron doped diamond (BDD). BDD film can reach resistivity of $<0.05 \Omega \cdot \mathrm{cm}$.

The reason why BDD electrodes attract much attention for stripping analysis of heavy metals is that they can be used within a very wide potential window. Peilin et al. [49] demonstrated that BDD has a slightly better sensitivity for lead $\left(3 \mathrm{nA} \cdot \mathrm{mm}^{-2} \cdot \mathrm{ppb}^{-1}\right)$ than glassy carbon electrode (GCE) $\left(2.4 \mathrm{nA} \cdot \mathrm{mm}^{-2} \cdot \mathrm{ppb}^{-1}\right)$, when both use in situ plated mercury. However, BDD without mercury plating exhibits three to five times lower sensitivity compared to mercury plated GCE [50]. With ASV, Manivannan et al. have reported that sub-ppb detection of lead is achievable using $-1 \mathrm{~V}$ deposition potential for 15 min [51-53]. Compton's group has shown that sonoelectrochemical treatment increased sensitivity for $\mathrm{Pb}$ [54], $\mathrm{Cd}$ [55], Mn [56] and $\mathrm{Ag}$ [57]. BDD electrodes have been successfully used for the simultaneous detection of mixtures of $\mathrm{HMs}: \mathrm{Pb}+\mathrm{Cd}+\mathrm{Ag}$ [58], $\mathrm{Zn}+\mathrm{Pb}+\mathrm{Cd}+\mathrm{Cu}$ [59], $\mathrm{Pb}+\mathrm{Cd}+\mathrm{Cu}+\mathrm{Hg}[60]$ and $\mathrm{Cd}+\mathrm{Ni}+\mathrm{Pb}+\mathrm{Hg}$ [61]. Hutton et al. have examined the factors controlling stripping voltammetry of lead at BDD using high-resolution microscopy [62]. They have shown that the deposition process was driven to produce a grain-independent homogeneous distribution of $\mathrm{Pb}$ nanoparticles on the electrode and that substantial amount of $\mathrm{Pb}$ remains on the surface after stripping, which explains the non-linear response at high concentrations. Prado et al. studied the interaction between $\mathrm{Pb}$ and $\mathrm{Cu}$ [63] during simultaneous detection by ASV. They observed the appearance of an extra peak which was attributed to hydrogen evolution on copper. They suggested that $\mathrm{Cu}$ deposition occurs preferentially, then $\mathrm{Pb}$ deposition takes place on already formed copper deposits which act as active sites for nucleation and growth process. This covers the copper with a solid film of lead. During the stripping step, oxidation of lead takes place first, so the copper deposits would be suddenly exposed to an acid electrolyte at a potential at which hydrogen evolution could take place. Manivannan et al. [64] studied the interaction between $\mathrm{Pb}$ and $\mathrm{Cd}$ during simultaneous detection (Figure 5A). They observed that in the presence of a constant concentration of $\mathrm{Pb}(5 \mu \mathrm{M})$, the peak currents for Cd were ca. $55 \%$ smaller than those obtained without $\mathrm{Pb}$. On the contrary, they also observed that in the presence of a constant concentration of $\mathrm{Cd}(5 \mu \mathrm{M})$, the peak currents for $\mathrm{Pb}$ were ca. $40 \%$ larger compared to those for $\mathrm{Pb}$ in the absence of $\mathrm{Cd}$. This behavior was explained through the model described above for $\mathrm{Pb}$ and $\mathrm{Cu}$, i.e., metals that have more negative standard potentials tend to deposit on metals that have less negative standard potentials. This explains the difference in peak current observed for $\mathrm{Cd}$ and $\mathrm{Pb}$. The authors proposed a 3D calibration curve to avoid cross-interference between these two metals (Figure 5B). 
(a)
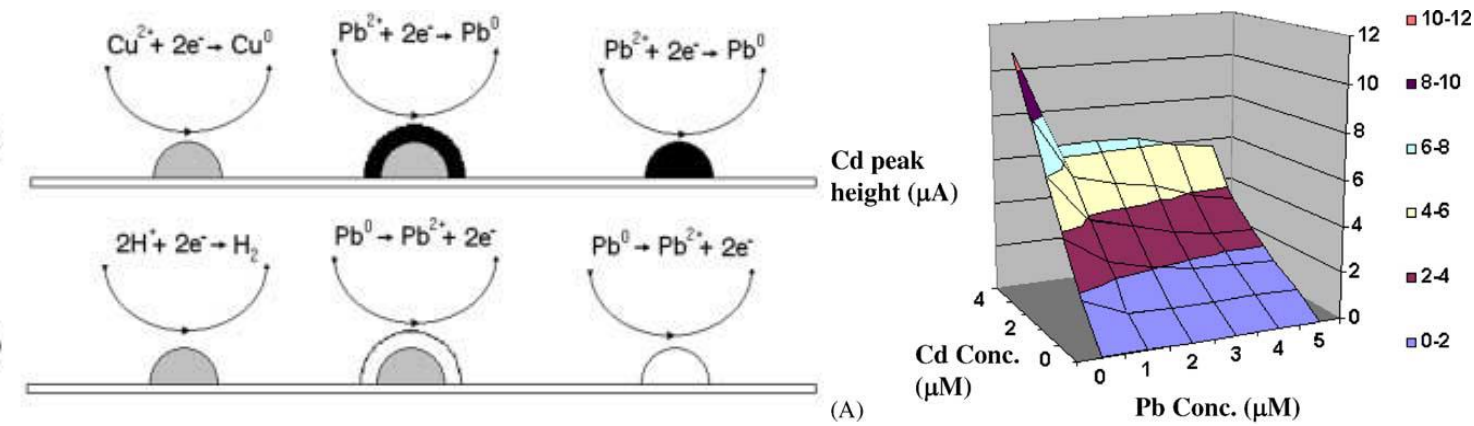

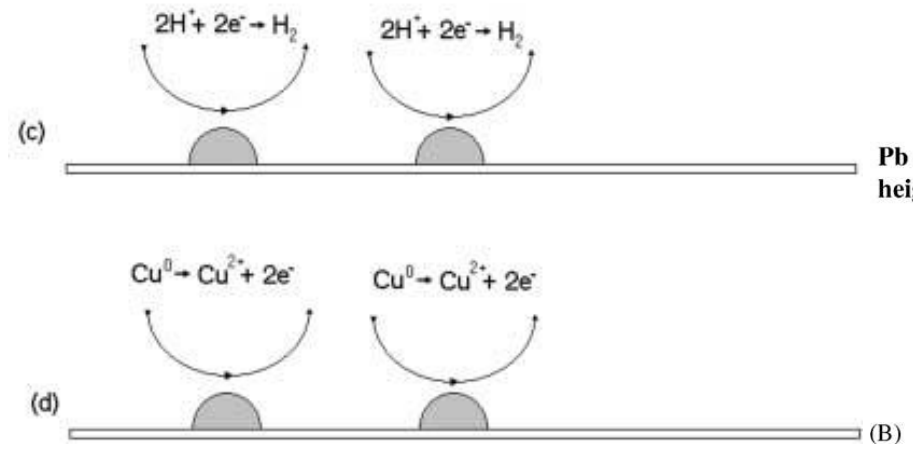

(A)

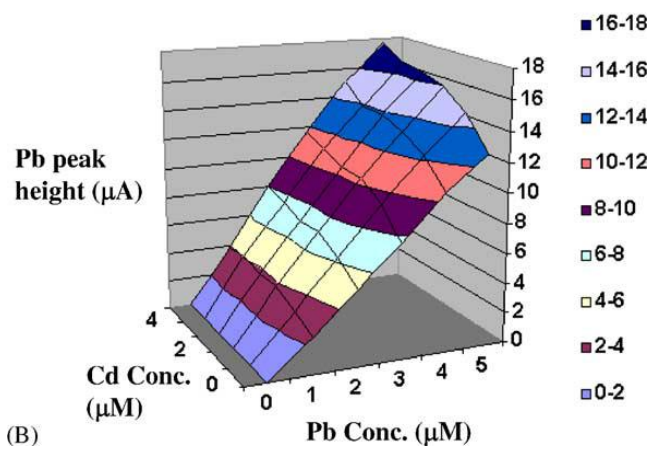

(B)

Figure 5. (A) Schematic diagram for the deposition and stripping processes. (a) The potential is maintained at $-1.0 \mathrm{~V}$ where lead and copper deposits are formed but the latter are quickly covered by reduced lead. (b) When scanning in the positive direction, lead is first oxidized, (c) leaving copper deposits exposed, and hydrogen evolution takes place. (d) Continuing scanning at potentials $\mathrm{E}>0.0 \mathrm{~V} \mathrm{Cu}$ deposits are oxidized; (B) Three-dimensional calibration curves for the differential pulse anodic stripping currents for (a) $\mathrm{Cd}$ (II) (b) $\mathrm{Pb}$ (II) in acetate buffer solutions containing both metals. Reprinted from [64], with permission from Elsevier.

\subsection{Diamond Like Carbon}

The use of BDD as electrode materials generates a great interest in the field of amorphous carbon or "diamond like carbon" (DLC) for electrochemical purpose. DLC films have electrochemical properties similar to those of BDD: low background current, wide potential window and high electronic transfer rate. Unlike BDD, DLC films exhibit the main advantage in being able to be synthesized at low temperatures (from ambient temperature to $200{ }^{\circ} \mathrm{C}$ ), so they can for example be integrated to glass microfluidic devices, for example. Amorphous carbon films have a microstructure which is a mix of $\mathrm{sp}^{2}$ and $\mathrm{sp}^{3}$ carbon. They can also contain hydrogen, depending on deposition conditions. A wide range of microstructures can be obtained with different $\mathrm{sp}^{2} / \mathrm{sp}^{3}$ carbon ratio and hydrogen content. Films with high level of $\mathrm{sp}^{3}$ carbon $(>40 \%)$ are called tetrahedral amorphous carbon (Ta-C). Various elaboration methods can be used: (i) ion deposition; (ii) filtered cathodic vacuum arc (FCVA); (iii) pulsed laser deposition which lead mainly to Ta-C films; (iv) sputtering; (v) plasma enhanced chemical vapor deposition (PECVD) which lead to amorphous carbon films containing higher level of $\mathrm{sp}^{2}$ carbons [65]. Zeng et al. [66] used sputtered DLC film for simultaneous detection of $\mathrm{Pb}, \mathrm{Cd}$ and $\mathrm{Cu}$. Khun et al. [67] and Liu et al. [68] used tetrahedral nitrogen doped amorphous carbon (Ta-C:N) for the detection of single elements like $\mathrm{Zn}, \mathrm{Cu}, \mathrm{Pb}$ and $\mathrm{Hg}$ and simultaneous detection of $\mathrm{Pb}, \mathrm{Cu}$ and $\mathrm{Hg}$ in deaerated and 
unstirred $\mathrm{KCl}$ solution, but the concentrations used were high ( $\mathrm{mM})$. Khadro et al. [69] used femto laser ablation to deposit undoped a-C and doped a-C:B (8\%) film onto $\mathrm{SiO}_{2}$ and $\mathrm{Si}_{3} \mathrm{~N}_{4}$ substrates. $\mathrm{Pb}, \mathrm{Ni}, \mathrm{Cd}$ and $\mathrm{Hg}$ were detected using SWASV. The effect of the boron doping was clearly evidenced for $\mathrm{Pb}$ detection: The $\mathrm{Pb}$ peak height increased by $20 \%$ with $8 \%$ of bore as dopant.

As a conclusion of this section dedicated to electrode materials, it has been proved that stripping voltammetry on metallic or carbon electrodes is very effective in detecting various heavy metals at sub-ppb levels even in real samples such as tap water. Such systems are also easily miniaturisable for on-field detection. Nevertheless, they present important drawbacks, such as in the exact determination of a concentration in presence of mixture of heavy metals, lack of reproducibility due to intermetallic compounds, to fouling of the electrode after measurements and the formation of biofilms. One solution to these drawbacks is to chemically modify the electrode surface in order to enhance selectivity and sensitivity or to prevent fouling; conducting polymers are excellent candidates for such electrode modifications.

\section{Conducting Polymer-Modified Electrodes}

Chemically modified electrodes (CMEs) have received increasing attention, because they enhance sensitivity and selectivity of electrochemical analysis techniques. Among various modification approaches, conducting polymers (CPs) have received considerable attention due to their superior electrical conductivities, good adhesion properties and easy preparation. In addition, CPs demonstrated also anti-fouling capability, which is an important practical advantage over conventional electrode materials.

\subsection{Unmodified Conducting Polymers}

Unmodified CP films may display intrinsic affinity to metal ions. For example, it was demonstrated that silver could be entrapped in polypyrrole film [70,71]. Polythiophene and its derivatives also show affinity with HMs. Zejli et al. electropolymerized poly(3-methylthiophene) (P3MT) on gold or sonogel electrodes [72,73]. Mercury(II) was preconcentrated from the solution into the P3MT-modified electrode at open-circuit potential, then differential pulse voltammetry (DPV) was used to reoxidize $\mathrm{Hg}^{\mathrm{O}}$; a linear dependence with mercury(II) concentration was obtained in the range $10^{-8}-4 \times 10^{-6} \mathrm{~mol} \cdot \mathrm{L}^{-1}$. Poly(3,4-ethylenedioxythiophene): polystyrenesulfonate (PEDOT:PSS) was also used towards lead ions detection [74] (Figure 6).

Recently, Liu et al. demonstrated a highly $\mathrm{Ag}^{+}$-sensitive electrochemical sensor made of GCE coated with a Langmuir-Blodgett film (LB) that contained polyaniline (PANi) doped with p-toluenesulfonic acid (PTSA) [75]. An advantage of CPs over bare GC electrodes was also reported by Wang et al. [76], who evidenced that the quantity of metal remaining on the surface of PANi/GCE was smaller than on the bare GCE after stripping, which improved the repeatability of the electrodes. In comparison with typical CPs such as PPy, PANi and PTh, CPs from aromatic diamines have lower electrical conductivity, but they have a unique ability to form stable complexes with HM ions. Many references reported that polydiaminonaphthalene (PDAN) could chelate $\mathrm{Cu}^{2+}$ [77,78], $\mathrm{Hg}^{2+}, \mathrm{Ag}^{+}$[79,80], $\mathrm{Se}$ (IV) [81] or $\mathrm{Pb}^{2+}$, probably via free - $\mathrm{NH}_{2}$ groups. For example, Majid et al. [82] used a poly(1,8-diaminonaphthalene)-modified electrode to detect $\mathrm{Pb}^{2+}$ by $\mathrm{ASV}$, with a preconcentration step at a potential of $-0.9 \mathrm{~V} v s$. $\mathrm{Ag} / \mathrm{AgCl}$ before 
anodic stripping in differential pulse mode. For a preconcentration time of $10 \mathrm{~min}$, they obtained a linear calibration from $4 \mathrm{pg} \cdot \mathrm{L}^{-1}$ to $2 \mathrm{ng} \cdot \mathrm{L}^{-1}$.

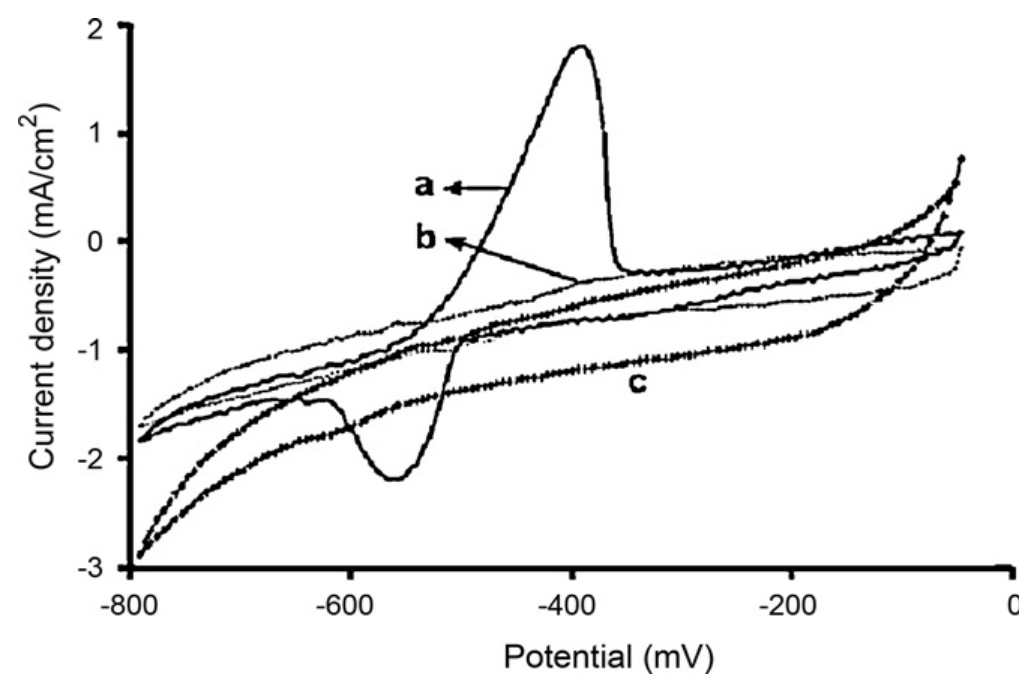

Figure 6. Cyclic voltammograms for $1 \mathrm{mM} \mathrm{Pb}{ }^{2+}$ in $0.05 \mathrm{~mol} \cdot \mathrm{L}^{-1} \mathrm{HCl}$ on: (a) PEDOT: PSS-modified electrode and (b) bare carbon electrode, compared with (c) lead-free electrolyte on PEDOT:PSS-modified electrode. Potentials $v s$. Ag/AgCl. Scan rate $10 \mathrm{mV} \cdot \mathrm{s}^{-1}$. Reprinted from [75], with permission from Elsevier.

\subsection{Modified Conducting Polymers}

As shown above, some CPs present intrinsic properties which may confer sensitivity and selectivity towards HMs; however, to improve these properties, they must be functionalized with ligands, for example, by making copolymers, by entrapment of known ionophores or using selected counter ions.

\subsubsection{Doping and Copolymerization}

The use of functional doping ions is probably the simplest way to functionalize CPs. For example, PPy membranes were deposited on GCE by electropolymerization of pyrrole in the presence of Eriochrome Blue-Black B (EBB) as counter anion [83]. The differential pulse anodic stripping voltammetry (DPASV) response of the EBB/PPy-modified electrode versus a bare GCE, both after preconcentration in $10^{-5} \mathrm{M} \mathrm{Ag}^{+}$at $-0.4 \mathrm{~V}$ for $200 \mathrm{~s}$, is shown in Figure 7A; the sensor showed a LoD of ca. $6 \times 10^{-9} \mathrm{M}$ for $\mathrm{Ag}^{+}$. Following the same idea, Lisak et al. described a polybenzopyrene film into which Eriochrome black $\mathrm{T}$ was entrapped, able to form complexes with $\mathrm{Pb}^{2+}$ ion [84]. In another study, a polythiophene-quinoline (PTQ)-modified electrode was used to detect copper and mercury. The redox behaviors of $\mathrm{Cu}(\mathrm{II})$ and $\mathrm{Hg}(\mathrm{II})$ were almost identical on this electrode, but the addition of 4-(2-pyridylazo)resorcinol (PAR) allowed the separation of the two cations due to the formation of a $\mathrm{Cu}$ (II)-PAR complex reduced at $-0.8 \mathrm{~V}$, whereas that of $\mathrm{Hg}$ (II) appeared at $-0.5 \mathrm{~V}$ vs. SCE. $\mathrm{Hg}$ (II) was detected down to $0.4 \mathrm{ppb}$ [85].

Copolymerization is also a simple way to functionalize CPs. For example, Somerset et al. showed that the presence of $\mathrm{Hg}^{2+}$ can be determined with a polyaniline-methylene blue (PANi-MB) copolymer [86]. The electrodes were prepared by electropolymerization of a mixture of aniline and 
methylene blue. A linear calibration curve was found in the range of $10^{-8} \mathrm{M}$ to $10^{-5} \mathrm{M} \mathrm{Hg}^{2+}$ using ASV. Copolymerization of ANi with 2,2'-dithiodianiline (DTDA) provided similar results [87]. In the case of $\mathrm{Cd}^{2+}$ and $\mathrm{Pb}^{2+}$, Philips et al. [88] developed a new copolymer poly(diphenylamine-co-2-aminobenzonitrile) and showed that it is efficient for detection of these ions down to $1.26 \mathrm{ppm}$ and $0.26 \mathrm{ppm}$, respectively (Figure 7B). Copolymers of aniline and imidazole were also reported to present a high sensitivity toward $\mathrm{Pb}^{2+}\left(2 \mu \mathrm{g} \cdot \mathrm{L}^{-1}\right)$ [89]. In another interesting example, authors described an electrode modified with overoxidized 2-mercaptoethanesulfonate (MES)-tethered polypyrrole, Nafion and bismuth, by analogy with bismuth thin-film electrodes described in Section 3.4 of this review [90]. SWASV was applied to detect $\mathrm{Pb}^{2+}$ and $\mathrm{Cd}^{2+}$ with LoDs of $0.03 \mu \mathrm{g} \cdot \mathrm{L}^{-1}$ and $0.04 \mu \mathrm{g} \cdot \mathrm{L}^{-1}$, respectively (Figure 8).

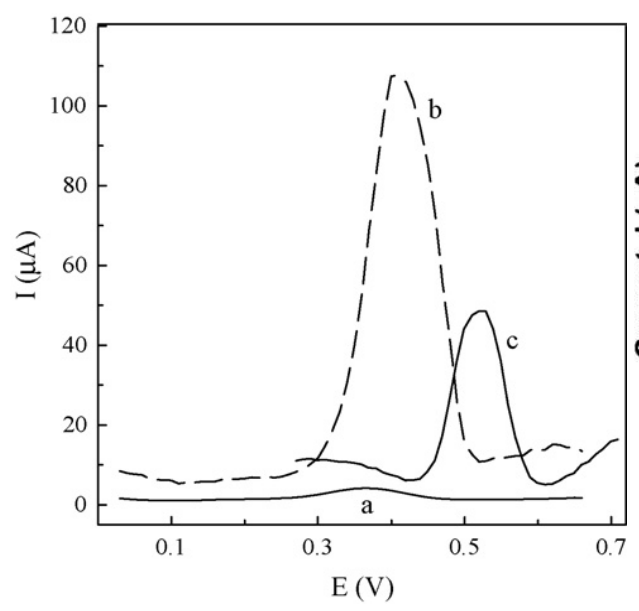

(A)

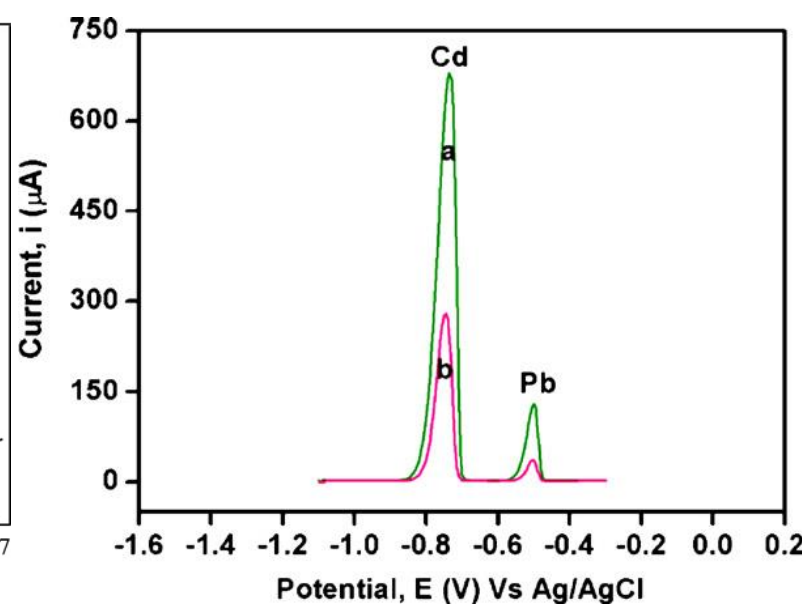

(B)

Figure 7. (A) DPASV response for a bare GC electrode (a) and for a EBB/PPy-modified electrode (b) after preconcentration in $10^{-5} \mathrm{M} \mathrm{Ag}^{+}$. The response of the electrode to $10^{-5} \mathrm{M}$ $\mathrm{Hg}^{2+}$ is also shown in (c). Reprinted from [83] with permission from Elsevier; (B) DPASV of the solution containing $\mathrm{Cd}^{2+}(12.8 \mathrm{ppm})$ and $\mathrm{Pb}^{2+}(16.6 \mathrm{ppm})$ recorded at (a) a poly (diphenylamine-co-2-aminobenzonitrile)-modified electrode and (b) poly(diphenylamine)modified electrode. Deposition potential $=-1.0 \mathrm{~V}$; deposition time $=60 \mathrm{~s} ; \mathrm{pH}=2.1$. Reprinted from [88] with permission from Elsevier.

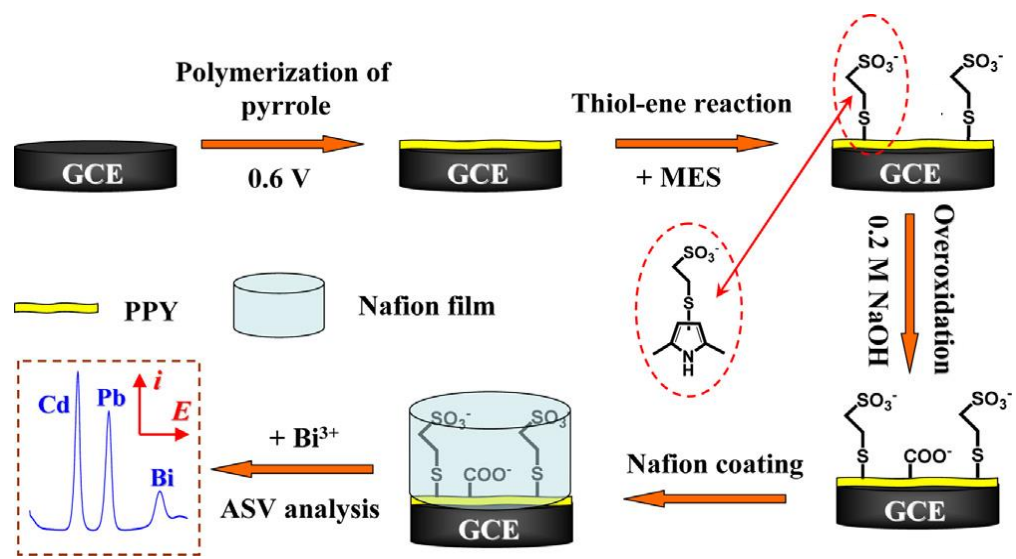

Figure 8. Schematic illustration of the procedures for preparing the Bi/Nafion/OPPy-MES/GCE for ASV analysis of $\mathrm{Cd}^{2+}$ and $\mathrm{Pb}^{2+}$ ions (not to scale). Reprinted from [90] with permission from Elsevier. 
Lastly, authors reported an innovative strategy using ion imprinting in electropolymerized poly(2-mercaptobenzothiazole) (MPMBT), for the detection of $\mathrm{Hg}^{2+}$ [91]. It consists of electropolymerization in presence of $\mathrm{Hg}^{2+}$, then removal of $\mathrm{Hg}^{2+}$ before the detection step (Figure 9A). SWASV on such $\mathrm{Hg}^{2+}$-imprinted MPMBT showed a LoD in the $\mathrm{nM}$ range (Figure 9B). They also showed that such electrode is insensitive to interferences for $\mathrm{Pb}^{2+}, \mathrm{Cd}^{2+}, \mathrm{Zn}^{2+}, \mathrm{Cu}^{2+}$ and $\mathrm{Ag}^{+}$.

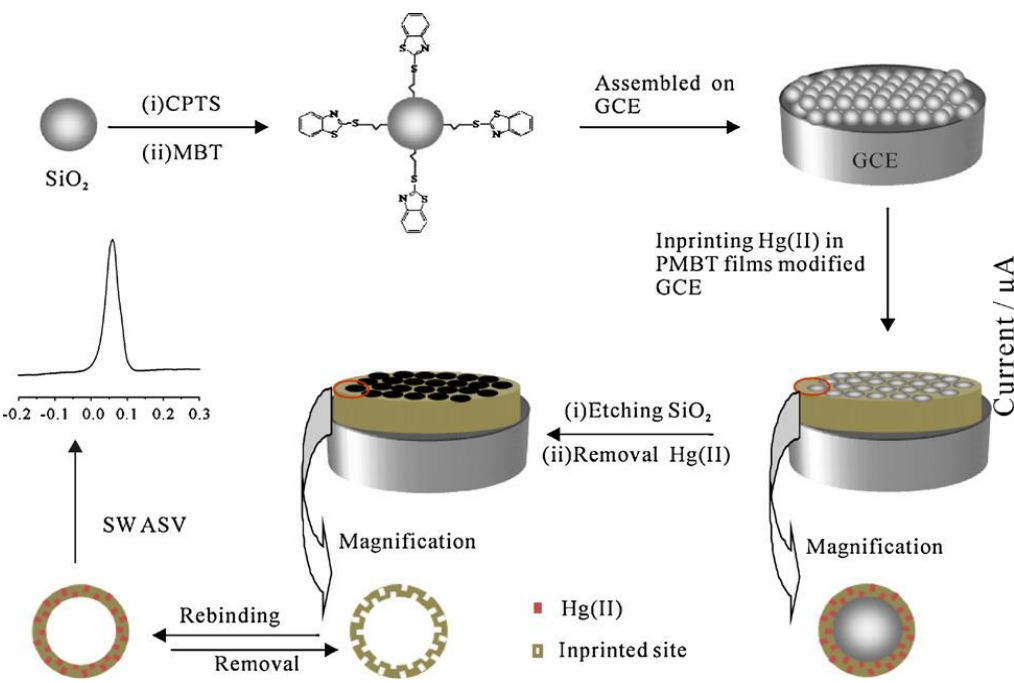

(A)

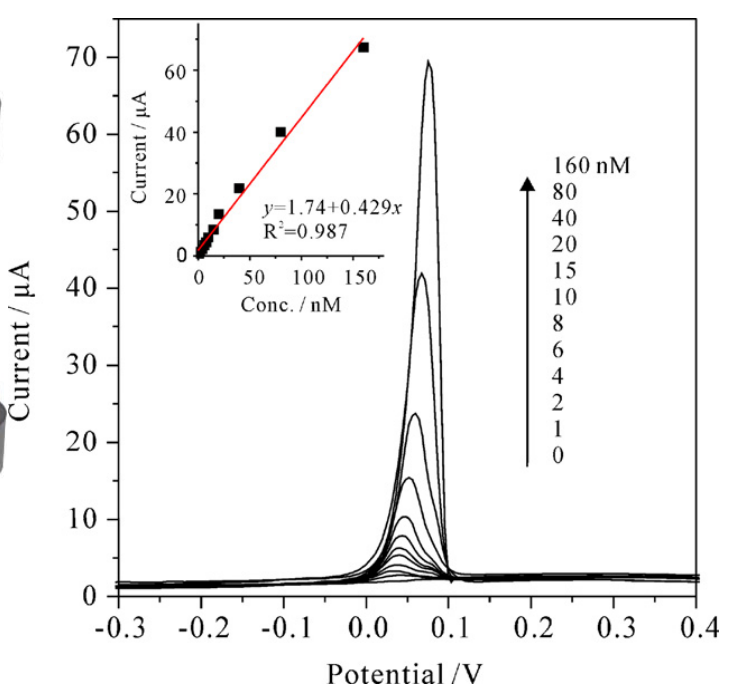

(B)

Figure 9. (A) Schematic representation of how $\mathrm{Hg}^{2+}$-imprinted MPMBT is obtained; (B) Typical SWASV of $\mathrm{Hg}^{2+}$ on an imprinted MPMBT. Preconcentration time: 8 min. Inset: calibration plot of the SWASV peak current $v s$. the $\mathrm{Hg}^{2+}$ concentration. Reprinted from [91] with permission from Elsevier.

\subsubsection{Grafting of a Complexing Agent}

Another possibility of modifying CPs is to graft the complexing agent on the polymer. For example, Rahman et al. reported the electropolymerization of 3',4'-diamino-2,2';5',2"-terthiophene onto which ethylenediaminetetraacetic acid (EDTA) was covalently coupled. EDTA is able to complex $\mathrm{Pb}^{2+}, \mathrm{Cu}^{2+}$ and $\mathrm{Hg}^{2+}$ ions during the preconcentration step, which was followed by reduction at $-0.9 \mathrm{~V}$ and reoxidation from $-0.9 \mathrm{~V}$ to $+0.75 \mathrm{~V}$. Linear calibration plots using SWV were obtained from $5 \times 10^{-10} \mathrm{M}$ to $10^{-7} \mathrm{M}$ for $\mathrm{Cu}^{2+}$ and from $7.5 \times 10^{-10} \mathrm{M}$ to $10^{-7} \mathrm{M}$ for $\mathrm{Pb}^{2+}$ and $\mathrm{Hg}^{2+}$, with corresponding LoD of $6 \times 10^{-10}, 2 \times 10^{-10}$ and $5 \times 10^{-10} \mathrm{M}$, respectively. Covered by a Nafion film, these electrodes were stable for more than one month [92]. Another example of conducting polymer modified by a complexing agent was given by Heitzmann et al. Poly( $N, N$-ethylenebis[ $N$-[(3-(pyrrole-1-yl)propyl) carbamoyl) methyl]glycine]), noted polyL, which was used for the electrochemical detection of $\mathrm{Cu}^{2+}, \mathrm{Pb}^{2+}$ and $\mathrm{Cd}^{2+}$, following the same protocol as for the previous example. Experiments showed that the polyL-modified electrodes were selective towards $\mathrm{Cu}^{2+}$ and insensitive to $\mathrm{Cd}^{2+}[93]$.

Stripping voltammetry is not the only reported method. Cortina-Puig et al. described overoxidized pyrrole-modified electrodes carrying ionophores specific for $\mathrm{K}^{+}, \mathrm{NH}_{4}{ }^{+}$for which electrochemical impedance spectroscopy was used for detection. The best results were obtained with dibenzo-18-crown- 6 as ionophore [94]. Conductometry was also reported for detection of $\mathrm{Hg}^{2+}$ using cryptand-222 as the 
receptor immobilized on PANi, with a LoD of ca. $10^{-12} \mathrm{M}$ [95]. As a last example, potentiometry was also used with polyaniline-modified electrodes onto which thiacalix[4] arene containing pyridine fragments was coupled, for determination of $\mathrm{Ag}^{+}$ions, however with a poor $\mathrm{LoD}$ in the $\mu \mathrm{M}$ range [96].

\subsubsection{CNT-Modified Conducting Polymers}

Carbon nanotubes (CNTs) have a large surface-to-volume ratio, good conductivity and strong adsorption ability that were proved to be useful for improving the sensitivity of sensors in general, and ions sensors in particular. Applying these properties, Wang et al. [97] used PANi-modified CNTs to detect $\mathrm{Pb}^{2+}$ by SWASV and found that CNT:PANI-coated electrodes had better performances than bare GCE. Other publications demonstrated that CNTs functionalized with aromatic amines are efficient for HMs adsorption. For example, Salmanipour et al. [98] functionalized GC electrodes with a mixture of multi-walled carbon nanotubes (MWCNTs) and 2-(5-bromo-2-pyridylazo)-5-diethylaminophenol (5-Br-PADAP) and detected $\mathrm{Pb}^{2+}$ by ASV in a range from 1 to $115 \mu \mathrm{g} \mathrm{L}^{-1}$. CPs/CNTs nanocomposites may also be made electrochemically. For example, Nguyen et al. [99] electropolymerized a mixture of PDAN and CNT on interdigitated arrays (Figure 10).

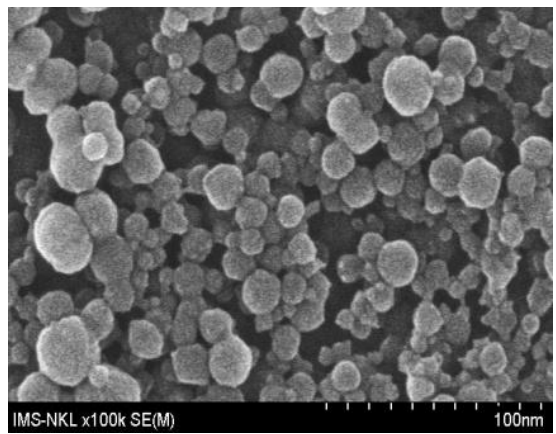

(A)

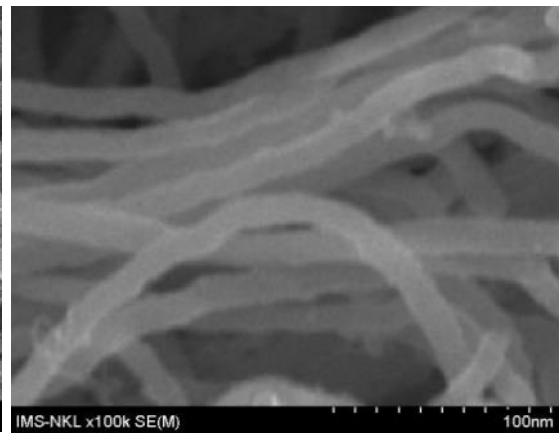

(B)

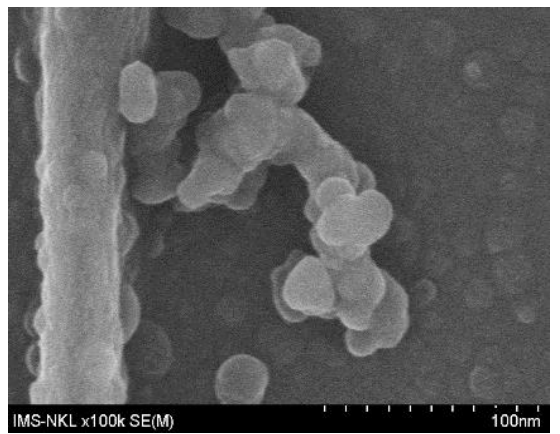

(C)

Figure 10. FE-SEM images of (A) PDAN; (B) pure CNT and (C) PDAN/CNT. Reprinted from [99] with permission from Elsevier.

Detection of $\mathrm{Hg}^{2+}$ was performed through preconcentration at open circuit potential followed by SWV. This sensor was specific for mercury because of the $\mathrm{Hg}^{2+} / \mathrm{Hg}_{2}{ }^{2+}$ redox potential with respect to that of PDAN/CNT. Figure 11 presents the corresponding SWVs and calibration curve. The same group also demonstrated a new approach to fabricate CPs/CNTs hybrid using a mixture of Nafion ${ }^{\circledR}$ (DuPont, Wilmington, DE, USA) and MWCNTs first deposited on the electrode surface, followed by 1,5-DAN electropolymerization [100,101], for determination of $\mathrm{Cd}^{2+}$ and $\mathrm{Pb}^{2+}$ by SWASV over the range $4-150 \mu \mathrm{g} \cdot \mathrm{L}^{-1}$ and $\mathrm{LoDs}$ of 3.2 and $2.1 \mu \mathrm{g} \cdot \mathrm{L}^{-1}$ for $\mathrm{Cd}^{2+}$ and $\mathrm{Pb}^{2+}$, respectively.

In conclusion, modification electrodes with CPs could improve their selectivity towards HMs and also their anti-fouling properties. CPs can be easily formed and controlled via electrochemical techniques; however, the main drawback of this type of electrodes concerns the relatively poor sensitivity which could be resolved by using suitable ionophores or CNTs, compared to sensitivities offered by metallic electrodes (Section 3). Another way to enhance selectivity is to directly use biomolecules, known to be extremely specific. To date, among all available biomolecules, enzymes, DNA, peptides or whole cells have been reported for ions sensors. 


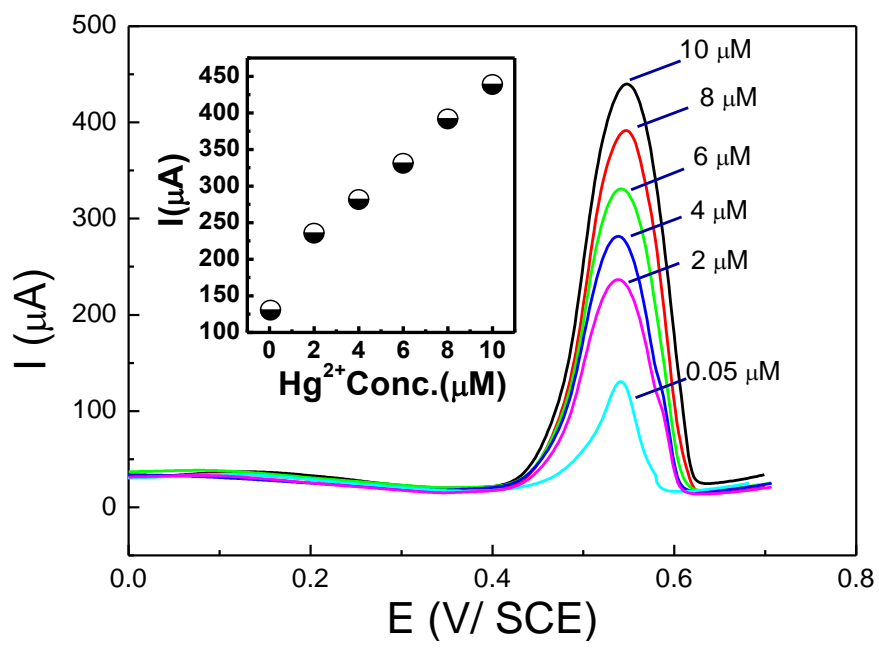

Figure 11. SWV curves, recorded on a PDAN/CNT-modified electrode, for various $\mathrm{Hg}^{2+}$ concentrations $(0.05-10 \mu \mathrm{M})$ and corresponding calibration curve (inset). Reprinted from [99] with permission from Elsevier.

\section{Electrodes Modified by Biomolecules}

In a biosensor, the sensitive and specific element is biological (e.g., microorganisms, cells or parts of cells, cell receptors, enzymes, nucleic acids, antibodies, peptides, etc.). This element must be interfaced with a transducer (in this review, we focus only on electrochemical detectors) that transforms the signal resulting from the interaction of the analyte with the biological element into a current (the interfacing between biomolecules or cells and sensors is a field of growing interest). High selectivity for the analyte, even in a matrix of other chemicals is a key requirement, which is particularly well met by bioreceptors.

Enzymes are characterized by their specific binding capabilities and catalytic activity. Analyte recognition is enabled through two possible mechanisms: conversion of the analyte into a product (although there is no example of HM ions being an enzyme substrate), or enzyme inhibition (a popular approach). With transduction, since enzymes are catalysts, they allow lower limits of detection compared to common binding techniques. As a drawback, enzymes have a limited lifetime.

DNA strands can also act as receptors for HM cations, due to their negative charge. DNA-cations recognition generally proceeds through encaging of the ions in local tertiary structures formed by self-pairing of a single strand. Recently, DNA-zymes (DNA sequences having catalytic properties) were described for HMs' detection, through similar mechanisms as classical enzymes.

Peptides are amino-acids sequences which, as in the case of DNA, may fold into specific spatial conformations, driven by hydrogen bonding, Van der Waals forces and, effectively, ionic interactions. Therefore, tertiary structures may be formed into which HM cations can bind. Moreover, like DNA, peptides can be synthesized and selected by automated routes in a combinatorial way, and are therefore extremely powerful receptors.

At last, cells may be used as bioreceptors because their metabolism is sensitive to their environment and can be easily monitored, e.g., through their respiration activity (oxygen consumption). They are commonly used to detect similar toxicity parameters. Among cells, microalgae are particularly efficient because their culture is relatively easy. 


\subsection{Enzymes}

Several enzymes such as acetylcholinesterase and alkaline phosphatase are extremely sensitive to a large number of heavy metals, which act as inhibitors. Enzyme inhibition may be of reversible or irreversible nature (see Figure 12 for the general inhibition mechanisms). For more details, the reader may refer to the review by Turdean [102].

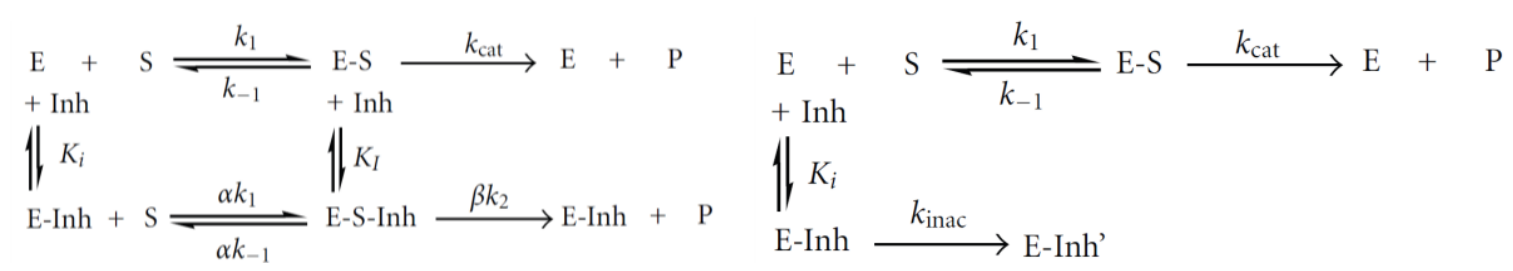

(A)

Figure 12. Processes of an enzyme for (A) a reversible inactivation or (B) an irreversible inactivation. E, enzyme; S, free substrate; $\mathrm{P}$, product; E-S, enzyme-substrate complex; E-Inh, enzyme inhibitor complex; E-S-Inh, ternary complex containing enzyme-substrate inhibitor; $\mathrm{K}_{\mathrm{I}}$ and $\mathrm{K}_{\mathrm{i}}$, equilibrium dissociation constants of the E-S-Inh complex and the E-Inh complex, respectively. Reproduced from [102] under Creative Commons Attribution License.

Enzyme products or by-products may be electroactive, meaning their activity may be followed by amperometry. Other enzymes produce or consume protons, meaning their activity can be monitored through $\mathrm{pH}$ changes. Other ions may also be produced; in this case, the enzyme's activity may be monitored through conductimetric measurements.

An excellent example of enzymes for HMs detection was given by Kukla in 1999 [103]. The authors developed a multi-enzyme electrochemical sensor array based on capacitance measurements, illustrated on Figure 13A. Selected enzymes (cholinesterase-BChE, urease-Ur or glucose oxidase-GOD) were immobilized on the array of electrodes, in order to quantify a large number of heavy metal ions among a mixture of these ions, simultaneously. An example of 3D-curves obtained from a three-enzyme device is given on Figure 13B.

(A)

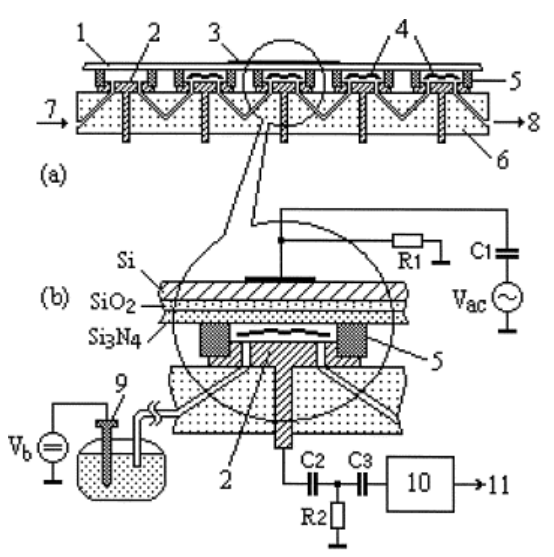

(B)

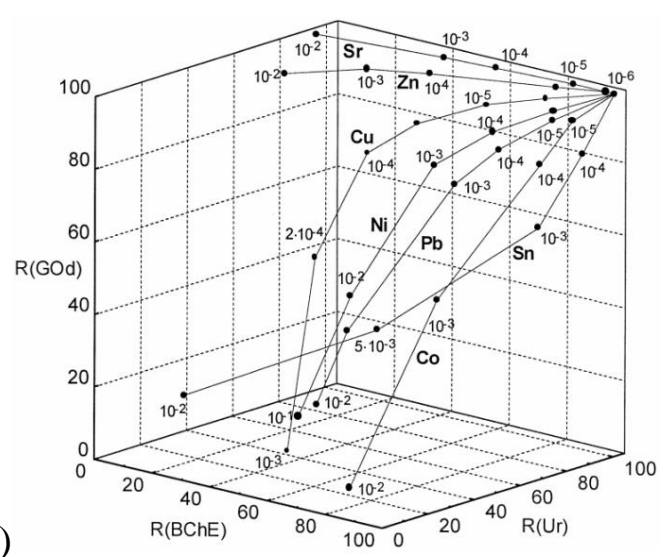

Figure 13. (A) 5-channel device with (1) sensitive $\mathrm{Si}-\mathrm{SiO}_{2}-\mathrm{Si}_{3} \mathrm{~N}_{4}$ sensors, (2) counter electrode, (4) enzymes, (5) sealing, (6) PMMA body, flow input (7) and output (8); (B) Residual activities for urease, $\mathrm{BChE}$ and GOD enzymes, respectively, after exposure to selected heavy metal ions at increasing concentrations. Reprinted from [103] with permission from Elsevier. 
In another example, Bagal-Kestwal et al. [104] reported an electrochemical biosensor using ultra-microelectrodes modified by invertase and glucose oxidase for the detection of $\mathrm{Hg}^{2+}, \mathrm{Ag}^{+}, \mathrm{Pb}^{2+}$ and $\mathrm{Cd}^{2+}$, with a detection limit of $\mathrm{Hg}^{2+}$ around $5 \times 10^{-10} \mathrm{M}$.

However, it is not the objective of this article to review the extensively investigated field of enzyme-inhibition sensors (the reader may refer to comprehensive review focusing on this topic) but to deal with emerging or less investigated receptors such as DNA, peptides, cells or algae.

\subsection{DNA}

DNA probes can be used for the development of HMs sensors as some heavy metals can form complexes with selected nucleic acid bases or structures. Three different strategies can be seen in the literature: coordination between $\mathrm{T}$ bases, DNAzymes and G-quadruplex.

\subsection{1. $\left(\mathrm{T}-\mathrm{Hg}^{2+}-\mathrm{T}\right)$ Coordination Based Sensors}

Thymine bases ( $\mathrm{T}$ ) can interact with $\mathrm{Hg}^{2+}$ to form $\mathrm{T}-\mathrm{Hg}$ - $\mathrm{T}$ structures which are even more stable than the Watson-Crick adenine-thymine pair [105]. Various electrochemical sensors for $\mathrm{Hg}^{2+}$ detection have been proposed using this approach [106-109]. For example, Liu et al. [110] have developed a simple strategy using poly-T oligonucleotides labeled with a ferrocenyl group and immobilized on the electrode surface via self-assembly of the terminal thiol moiety (Figure 14A). In the presence of $\mathrm{Hg}^{2+}$, a pair of poly- $\mathrm{T}$ oligonucleotides can cooperatively coordinate with $\mathrm{Hg}^{2+}$, which triggers a conformational reorganization of the poly-T oligonucleotides from flexible single strands to relatively rigid duplex-like complexes, thus drawing the ferrocenyl tags away from the electrode with a substantial decrease of the redox current.

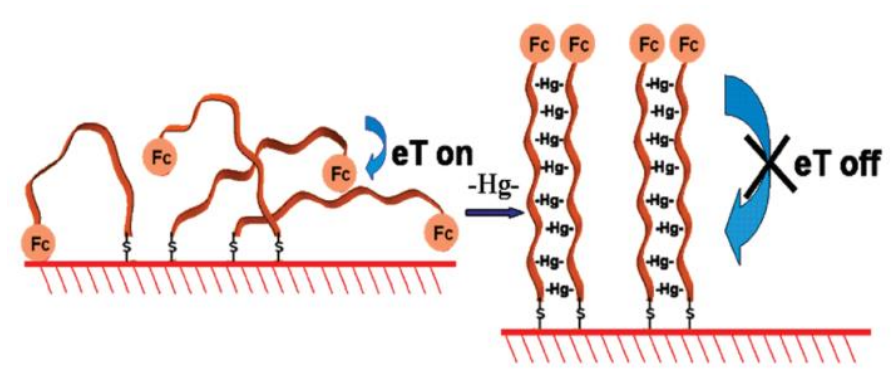

(A)

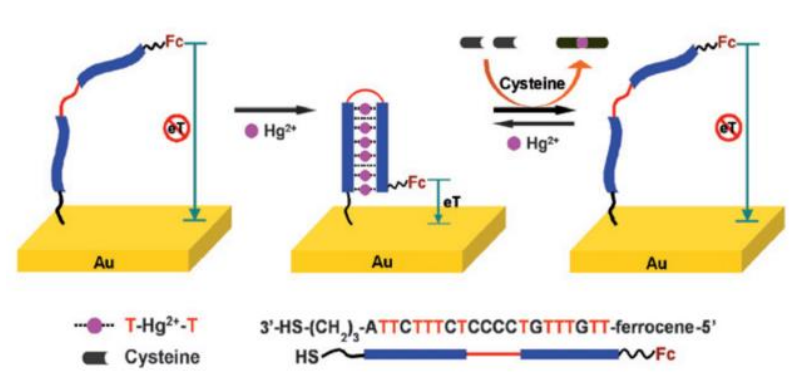

(B)

Figure 14. (A) Poly-T oligonucleotides tethered on one end on the electrode surface, and labeled on the other end with a ferrocenyl moiety. Upon addition of $\mathrm{Hg}^{2+}$, poly- $\mathrm{T}$ strands become rigid, drawing Fc away from the surface. Reprinted with permission from [110]. Copyright 2009 American Chemical Society; (B) DNA strand carrying a ferrocenyl tag at one end and immobilized on a gold electrode at its other end by a SH group. Under this conformation, the ferrocene is far from the surface and no current flows. A hairpin structure is induced if $\mathrm{Hg}^{2+}$ are present, by association between two $\mathrm{T}$ bases, which brings the Fc label close to the electrode surface. The sensor can be regenerated by simply unfolding the ferrocene-labeled DNA in $10 \mu \mathrm{M}$ cysteine. Reproduced from [111] with permission of The Royal Society of Chemistry. 
Han et al. [111] have developed an approach using a single-stranded DNA hairpin structure with T-T mismatch, labeled with a ferrocenyl tag and immobilized onto polycrystalline gold surface through self-assembled S-Au bonding. Addition of $\mathrm{Hg}^{2+}$ induces conformational change from an open structure to a restricted hairpin structure leading to the increase of the electrochemical signal due to ferrocene (Figure 14B). A detection limit of $0.1 \mu \mathrm{M}$ was obtained. This system could be reused after addition of $10 \mu \mathrm{M}$ of cysteine. Zhuang et al. [112] used the same kind of strategy but with a hairpin structure labeled with ferrocene in the middle of the loop. Addition of $\mathrm{Hg}^{2+}$ opens the hairpin resulting in the ferrocenyl tag close to the electrode to increase in redox current. Detection limit of $2.5 \mathrm{nM}$ was obtained. This system could be reused after addition of iodide. Wu et al. [113] obtained a limit of detection of $0.06 \mathrm{nM}$ using an immobilized single-stranded $\mathrm{DNA}_{1}$ hybridized with a second $\mathrm{DNA}_{2}$ strand labeled with ferrocenyl, which leads to high redox current. In the presence of $\mathrm{Hg}^{2+},\left(\mathrm{T}-\mathrm{Hg}^{2+}-\mathrm{T}\right)$ base pairs induced the folding of the oligonucleotide \#1 into a hairpin structure, resulting in the release of the ferrocenyl-tagged oligonucleotide \#2 from the electrode surface with a substantially decreased redox current.

\subsubsection{DNAzymes-Based Sensors}

DNAzymes are DNA sequences having the property to catalyze specific chemical and biological reactions, such as cleavage of the ribonucleic acid target. Some DNAzymes use divalent metal ion as cofactors; in the presence of this metal ion, the substrate is irreversibly cleaved into two fragments at the cleavage site [114]. Recently, DNAzymes have been used for the detection of lead [115-117] and copper [118]. Xiao et al. [119] have proposed a very elegant method for lead detection based on the use of a surface-immobilized, methylene-blue modified DNAzyme assembly (Figure 15). Without $\mathrm{Pb}^{2+}$, DNAzyme adopts a hairpin structure with the methylene blue away from the surface. In the presence of $\mathrm{Pb}^{2+}$, the substrate strand was cleaved. Therefore, the released enzyme strand become more flexible and facilitates the electron transfer between methylene blue and the electrode. The signal is proportional to the concentration of $\mathrm{Pb}^{2+}$ and the detection limit is $300 \mathrm{nM}$ (Figure 16A,B).
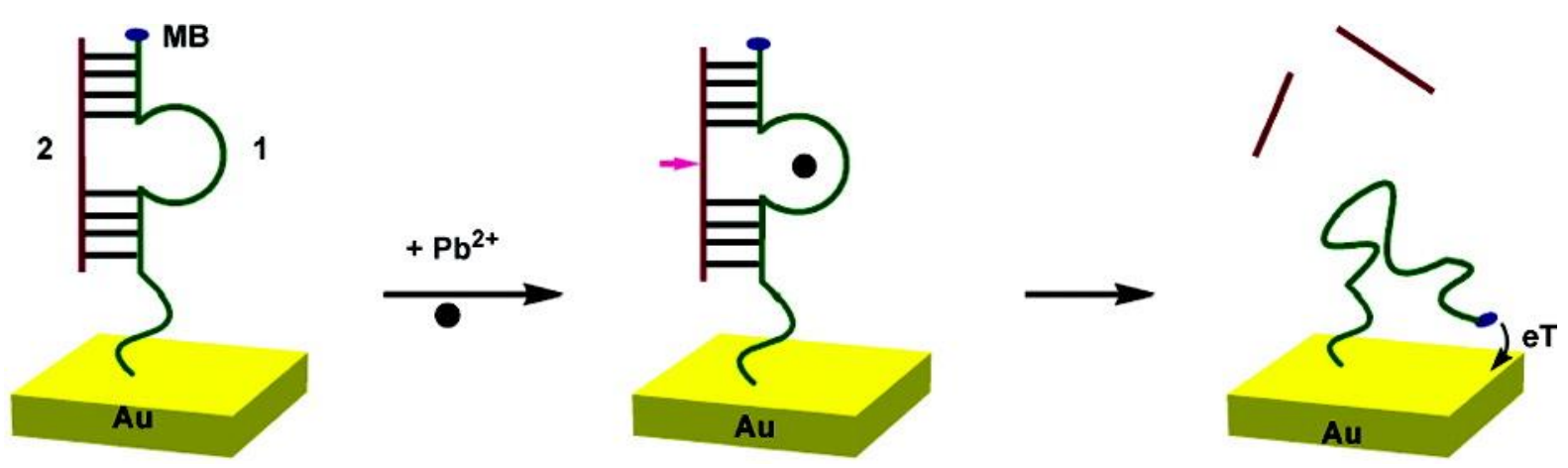

Figure 15. Scheme of the DNAzyme-based electrochemical sensor. Upon addition of $\mathrm{Pb}^{2+}$, the $\mathrm{DNA}_{2}$ is cleaved, which gives more freedom to MB-labeled DNA 1 . Reprinted with permission from [119]. Copyright 207 American Chemical Society.

This sensor was sufficiently specific and selective that it could be used in experiments with complex matrixes such as soil extracts, into which given quantities of $\mathrm{Pb}^{2+}$ were added. The results obtained were comparable to those obtained from simpler matrixes such as aqueous buffer (Figure 16C,D). 

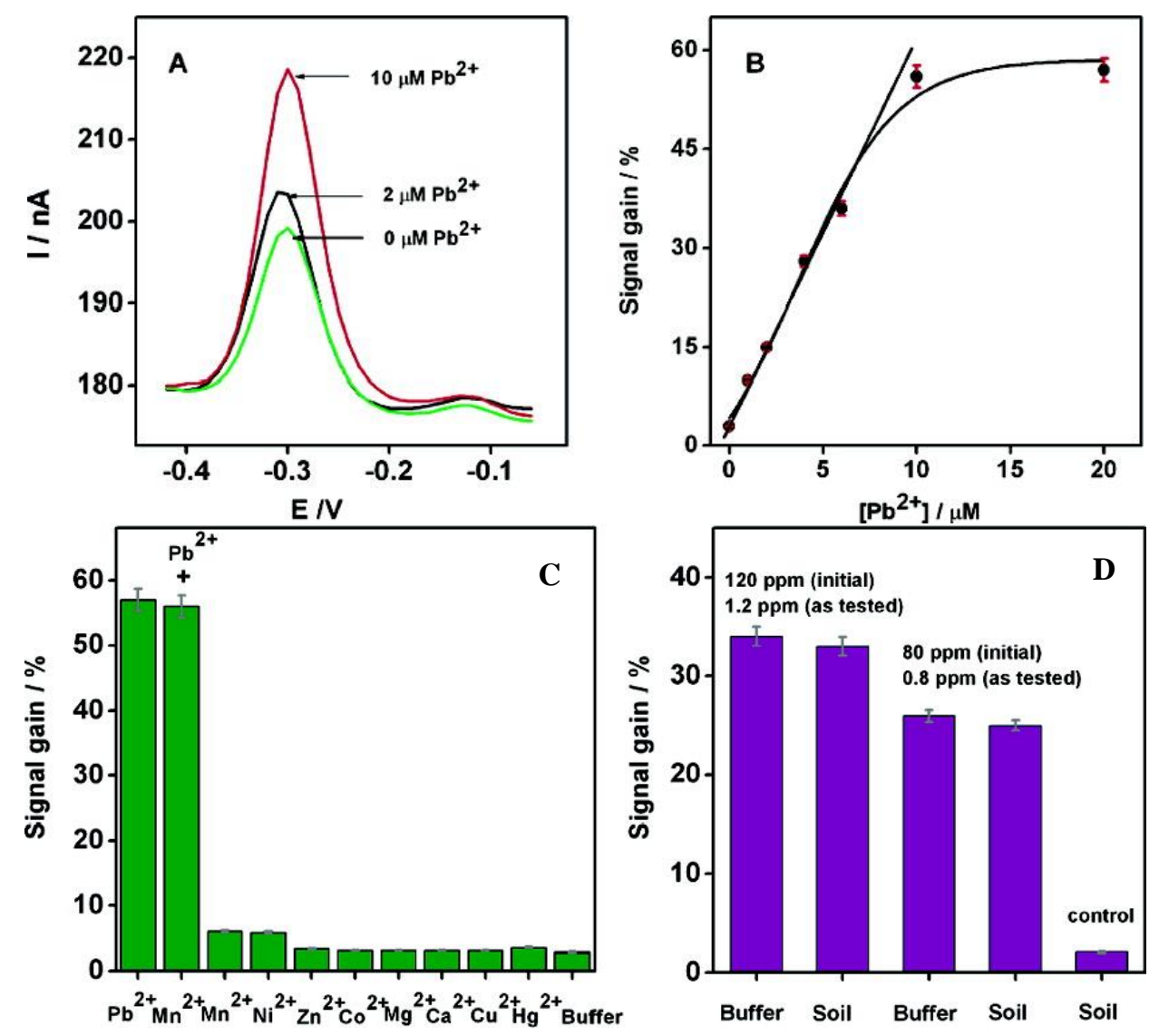

Figure 16. (A) Square wave voltammograms after $1 \mathrm{~h}$ incubation at increasing concentrations of $\mathrm{Pb}^{2+}$; (B) Calibration curve; (C) Specificity and selectivity experiments; (D) Current changes obtained from soil extracts spiked with given lead concentrations, versus control. Reprinted with permission from [119]. Copyright 207 American Chemical Society.

\subsubsection{G-Quadruplex-Based Sensors}

DNA G-quadruplex are nucleic acid sequences rich in guanine and capable of forming a four-stranded structure, which is stabilized in the presence of a cation such as $\mathrm{K}^{+}, \mathrm{Na}^{+}$or $\mathrm{Pb}^{2+}$. In 2011, Lin et al. [120] proposed an approach using an immobilized unlabeled DNA strand for the detection of $\mathrm{Pb}^{2+}$. In the presence of $\mathrm{Pb}^{2+}$, the guanine-rich strands switched from a random coil to a quadruplex structure, which was followed by impedance spectroscopy spectroscopy, which lead to a decrease in the charge transfer resistance. A LoD of $0.5 \mathrm{nM}$ was reached. Li et al. [121] developed a similar approach using crystal violet as a quadruplex redox binding indicator (crystal violet intercalates into DNA strands). The same approach was used very recently by Jarczewska et al. [122] who performed tests in real water, using impedance spectroscopy and methylene blue (MB) as external redox intercalator. Due to the fact that the G-quadruplex induces a folding of the DNA strands, the redox signal coming from $\mathrm{MB}$ rises upon addition of $\mathrm{Pb}^{2+}$, with a $\mathrm{LoD}$ of ca. $50 \mathrm{nM}$. Without evidencing the same G-quadruplex structure, Lian et al. [123] described a differential pulse voltammetry sensor based on the interaction of $\mathrm{Pb}^{2+}$ with DNA strands wrapped around single-walled carbon nanotubes (SWNT), with $\left.\mathrm{Fe}(\mathrm{CN})_{6}\right]^{3-/ 4-}$ acting as redox indicator in solution. They demonstrated a LoD of ca. $10^{-10} \mathrm{M}$ in buffer solution ( $\mathrm{pH}$ 5.0). 


\subsection{Peptides}

Peptides and amino acids have been studied for a long time as recognition elements for heavy metal ion detection, in particular for electrochemical sensors [124]. The 20 major amino acids are: alanine (A), Arginine (R), asparagine (N), aspartic acid (D), cysteine (C), glutamic acid (E), glutamine (Q), glycine (G), histidine $(\mathrm{H})$, isoleucine $(\mathrm{I})$, leucine $(\mathrm{L})$, lysine $(\mathrm{K})$, methionine $(\mathrm{M})$, phenylalanine $(\mathrm{F})$, proline $(\mathrm{P})$, serine $(\mathrm{S})$, threonine $(\mathrm{T})$, tryptophan $(\mathrm{W})$, tyrosine $(\mathrm{Y})$ and valine $(\mathrm{V})$. Recent articles reported innovative devices or approaches. For instance, Viguier et al. [125] described nanofibrils of four octapeptides (NSGAITIG, NCGAITIG, CNGAITIG, CSGAITIG) having self-assembling properties, which demonstrated recognition capabilities for copper ions. The authors claimed a LoD of ca. $20 \mu \mathrm{M}$ using cyclic voltammetry, but did not describe the mechanisms involved. Recently, a heptapeptide (TNTLSNN) was identified to selectively bind $\mathrm{Pb}^{2+}$ and subsequently immobilized on top of a nanoporous gold electrode [126] through electrodeposition of poly(thiopheneacetic acid) followed by covalent coupling via amide linkage (Figure 17A). After preconcentration by the peptide, $\mathrm{Pb}^{2+}$ was detected using ASV, with a LoD of ca. $1 \mathrm{nM}$ (Figure 17D).

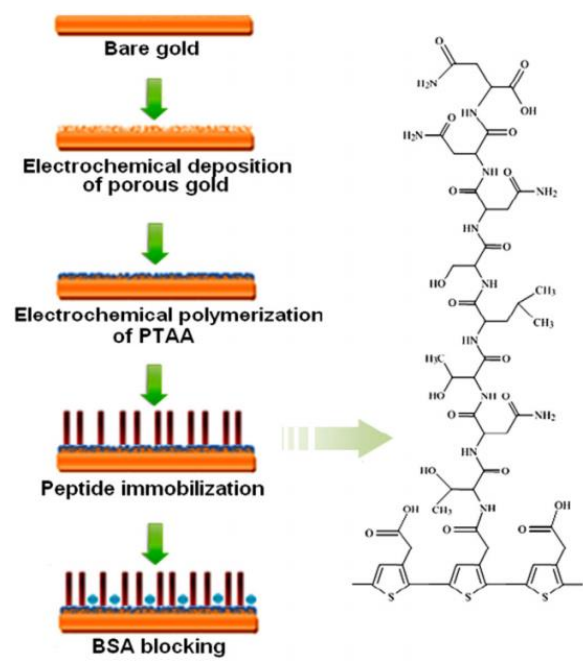

(A)

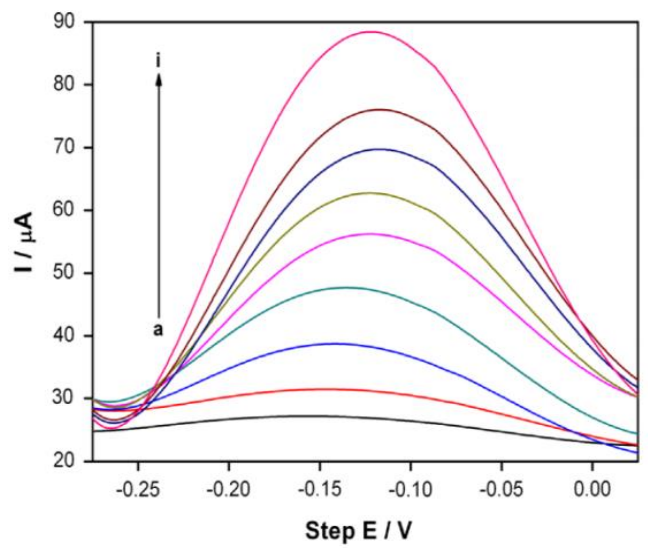

(C)
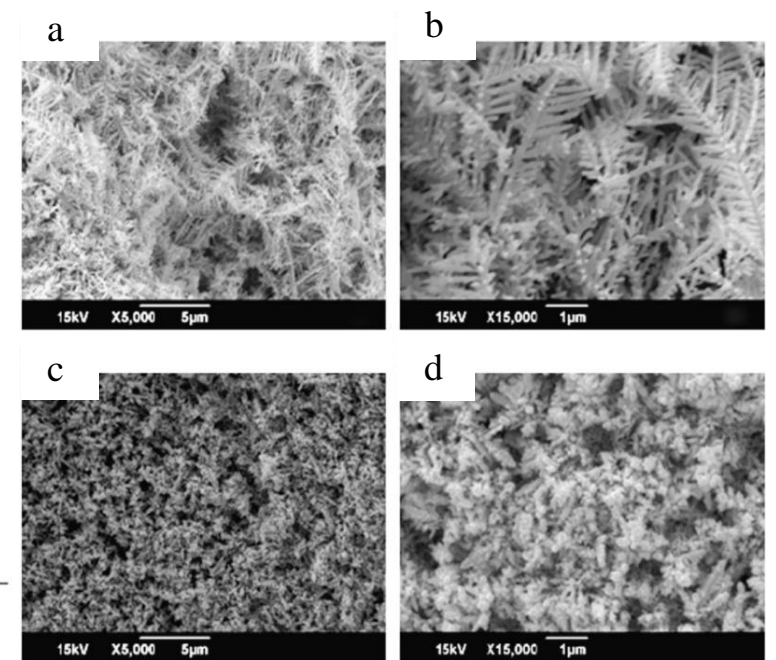

(B)

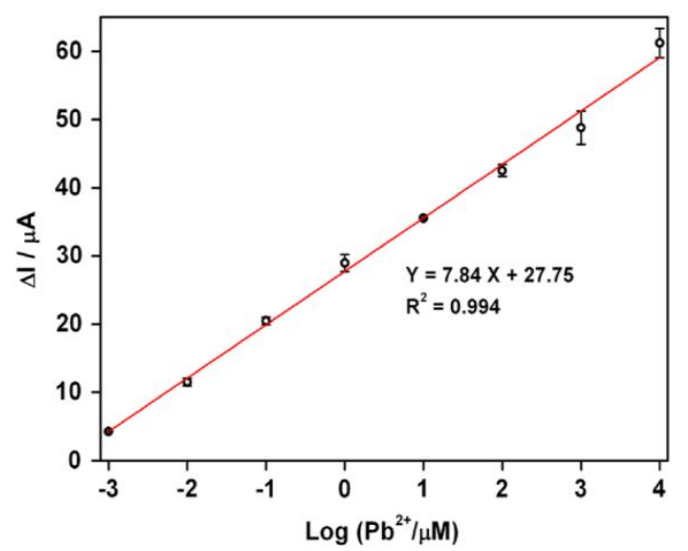

(D)

Figure 17. (A) Scheme of the procedure for fabricating the peptide modified electrode; (B) SEM images of porous gold ( $\mathrm{a}$ and $\mathrm{b}$ ) and PTAA-covered porous gold (c and d) layers at different magnifications; (D) SWVs with $\mathrm{Pb}^{2+}$ concentration from $1 \mathrm{nM}-10 \mathrm{mM}$; (D) Calibration curve. Reprinted from [126] with permission from Elsevier. 
Very recently, Serrano et al. [127] reported a three-electrode device in which each electrode was functionalized with a different peptide (glutathione, Cys-Gly and $\gamma$-Glu-Cys) through aryl diazonium electrografting. $\mathrm{Cd}^{2+}, \mathrm{Pb}^{2+}$ and $\mathrm{Zn}^{2+}$ were determined with this device, using differential pulse adsorptive stripping voltammetry (Figure 18).

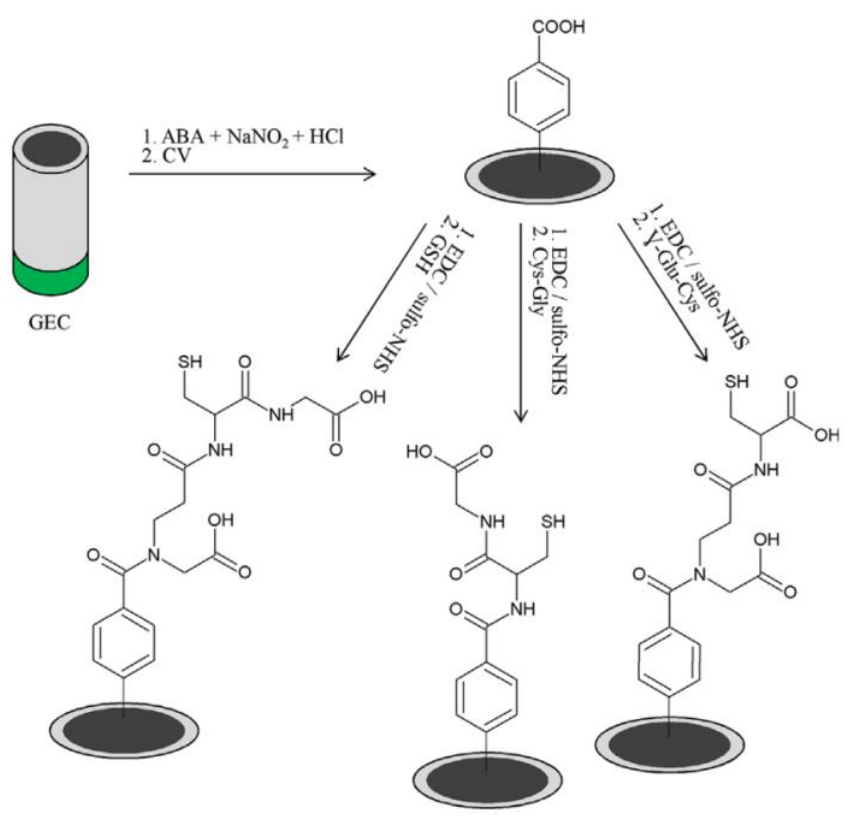

(A)

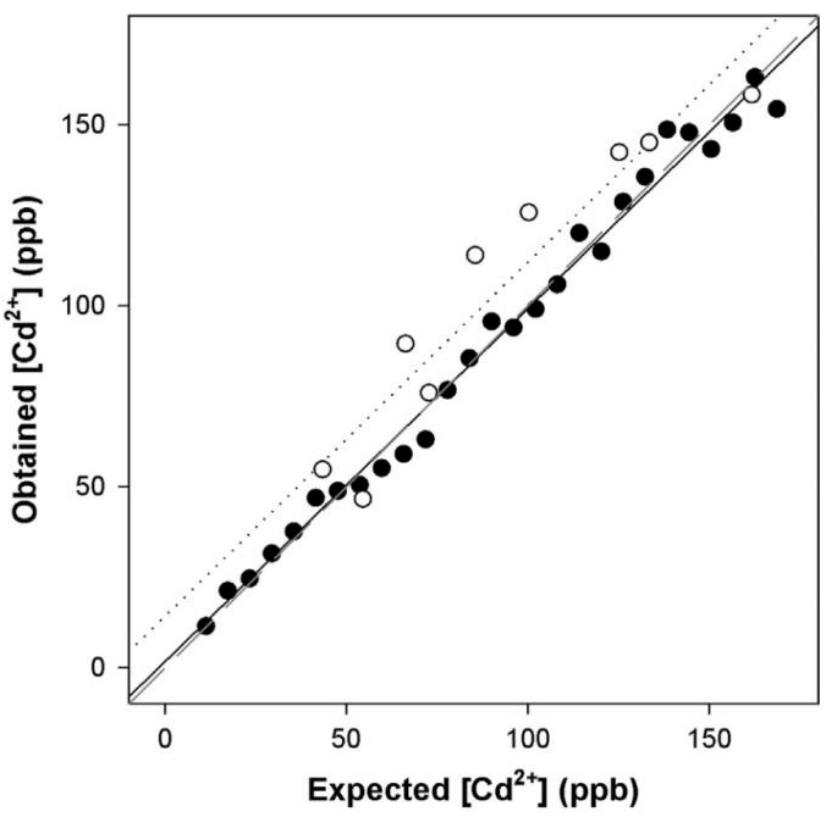

(B)

Figure 18. (A) GSH, $\gamma$-Glu-Cys and Cys-Gly electrografting; (B) Measured vs. expected concentrations for $\mathrm{Cd}^{2+}$. The LoD is below $20 \mathrm{ppb}$. Reprinted from [127] with permission from Elsevier.

A mathematical treatment of the currents measured at each electrode was applied to eliminate interferences, so that simultaneous determination of these three heavy metal ions was achieved. GSH has shown the best sensitivity, followed by Cys-Gly and $\gamma$-Glu-Cys.

\subsection{Whole Cells}

Detection of heavy metal ions using whole cells has been described since several decades, mostly using optical transduction techniques such as fluorescence (cells fluoresce in response to a target.). However, these approaches need marking, which has disadvantages, such as complexity and high cost [128]. Living cells are particularly useful for detection of traces of environmentally toxic compounds because these molecules or ions interfere with one or several internal biological processes (e.g., photosynthesis) and produce a modification of the cell's activity. The major difference between living cells-based biosensors and classical biosensors is the same as between a canary in a coalmine and a methane or carbon monoxide sensor: the sensor will detect only methane or carbon monoxide, but the canary will detect both, often with a better reliability. Similarly, trouts are known to be particularly sensitive to river water pollution, although not necessarily to a single pollutant, and in a physiologically relevant manner [129]. The problems arising with the use of living animals, aside from ethics, are that their interfacing with electronic transducers is particularly unstable, obliterating any quantification 
possibilities, whilst cells can be immobilized on a surface and used as active sensing elements. From this point of view, owing to its simple instrumentation, high sensitivity and low-cost, electrochemical transduction is particularly pertinent. Indeed, it is relatively easy to immobilize whole cells on electrodes and electrochemically monitor redox species which participate in the cells' living processes, e.g., oxygen, hydrogen peroxide or protons [130-133].

Adam et al. [134] have described an electrochemical method for studying the behavior of Escherichia coli that is modified in order to express the human metallothionein gene (MT-3). MT-3 is a cysteine-rich protein known to bind metal ions; after exposure of the bacteria to heavy metal ions, metallothionein was isolated using fast protein liquid chromatography and quantified by electrochemical methods (through typical cysteine oxidation). Its interactions with cadmium and lead ions showed a decline in electrochemistry due to metal ions binding to cysteine. Zhu et al. [135] reported a label-free electrochemical method based on the direct voltammetric response of human cervical carcinoma (HeLa) cells on a reduced graphene oxide-modified glassy carbon electrode. Five heavy metals were tested $(\mathrm{Cr}, \mathrm{Cd}, \mathrm{Cu}, \mathrm{Pb}, \mathrm{Zn})$ with an excellent correlation using a traditional quantification assay. Actually, the method is cell counting, which is based on the quantity of guanine and xanthine secreted in the cell suspension and oxidized on the electrode, yielding an anodic potential of around $+0.67 \mathrm{~V} v s . \mathrm{Ag} / \mathrm{AgCl}$ (Figure 19).

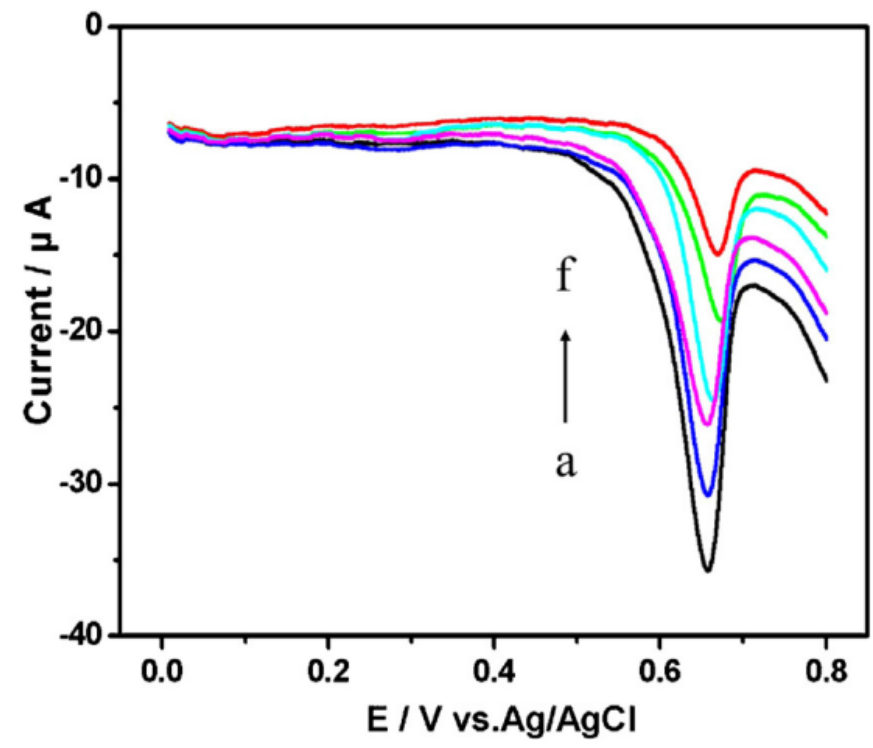

(A)

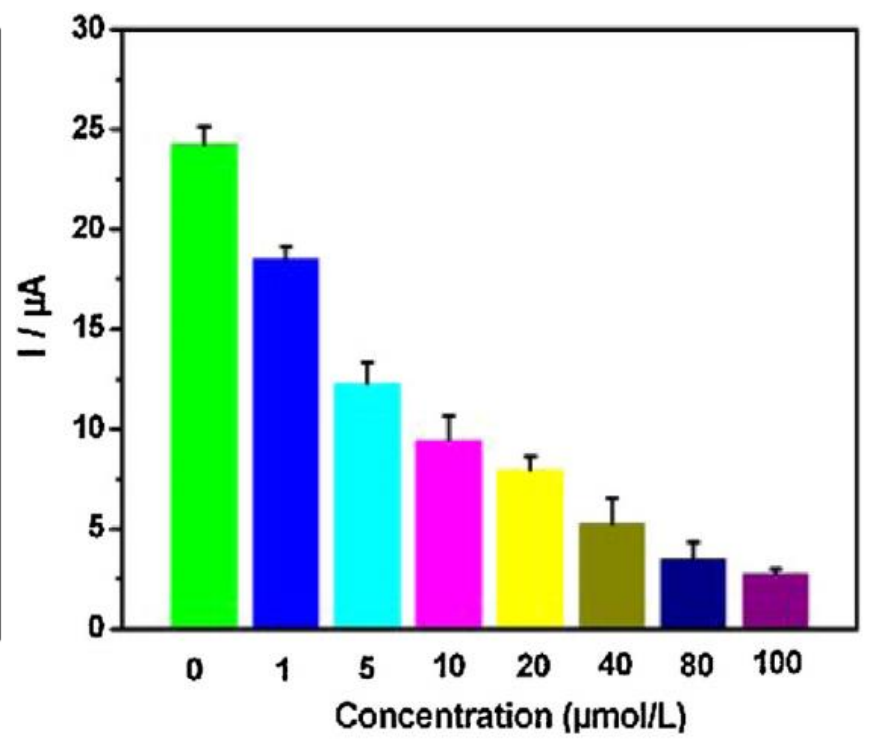

(B)

Figure 19. (A) CVs of HeLa cell suspension $\left(2.0 \times 10^{5}\right.$ cells $\left.\cdot \mathrm{mL}^{-1}\right)$ treated during $30 \mathrm{~h}$ with $20 \mu \mathrm{M}$ of heavy metals solutions. (a) no $\mathrm{HM}$, (b) $\mathrm{Zn}^{2+}$, (c) $\mathrm{Pb}^{2+}$, (d) $\mathrm{Cu}^{2+}$, (e) $\mathrm{Cd}^{2+}$, (f) $\mathrm{Cr}^{6+}$; (B) Peak currents obtained after exposure to different concentrations of $\mathrm{Cr}^{6+}$. Reprinted from [135] with permission from Elsevier.

Liu et al. [136] described a novel biosensor for monitoring the changes in electrophysiological activity upon heavy metal exposure. They developed a light-addressable potentiometric sensor (LAPS) [137,138] based on cardiomyocytes immobilized on a semiconductor. Upon illumination of the semiconductor through the cardiomyocytes, the latter produce an ionic current and also change their shape, which lead to a fluctuation of the photocurrent (Figure 20A). After being exposed to different 
heavy metal ions $\left(\mathrm{Hg}^{2+}, \mathrm{Pb}^{2+}, \mathrm{Cd}^{2+}, \mathrm{Fe}^{3+}, \mathrm{Cu}^{2+}, \mathrm{Zn}^{2+}\right)$, cardiomyocytes demonstrated characteristic changes in terms of beating frequency, amplitude and duration under the different toxic effects of ions, in less than $15 \mathrm{~min}$. The limit of detection depends on the metal, but sits between $1 \mu \mathrm{M}$ and $10 \mu \mathrm{M}$ (Figure 20B). This technique paves the way to new bio-analytical methods, instrumentation and cell-based assays for in vitro toxicity screening.

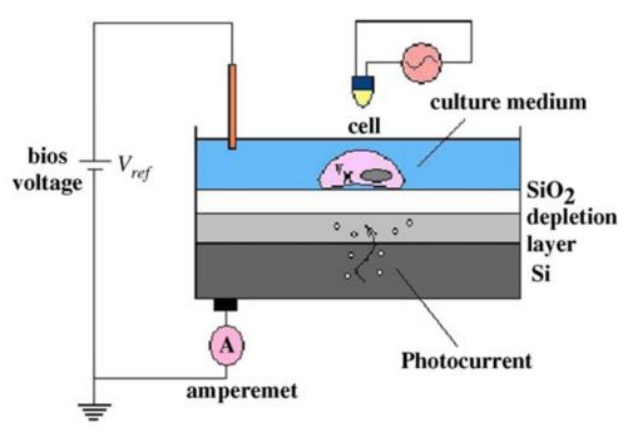

(A)

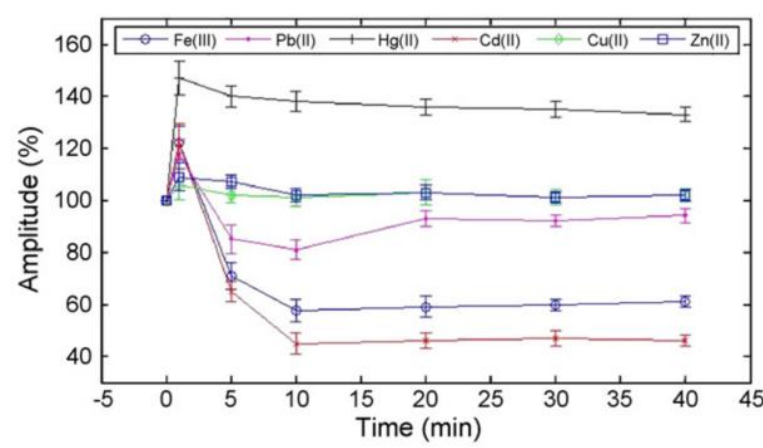

(B)

Figure 20. (A) Schematic drawing of a LAPS device to monitor beating of cardiomyocytes immobilized on the semiconductor layer. The light pointer is focused above the LAPS, and illuminates vertically above the desired cells. Depending on the bias voltage, photocurrent of the LAPS is monitored by the detection system through peripheral circuit; (B) Effect of heavy metals on the spontaneous beating amplitude of the cardiomyocytes recorded by LAPS (mean \pm S.E.M.; $n=7$ ). Reprinted from [136] with permission from Elsevier.

Micro-algae such as chlorophyta, cyanobacteria and diatoms are also very sensitive to changes in their environment, enabling the detection of traces of pollutants [139]. Tsopela et al. [140] described a microfabricated electrochemical biosensor (Figure 21) containing three types of electrode materials ( $\mathrm{Pt}$ black, $\mathrm{Pt} / \mathrm{IrO}_{2}$ and $\mathrm{W} / \mathrm{WO}_{3}$ ), which are able to detect $\mathrm{O}_{2}, \mathrm{H}_{2} \mathrm{O}_{2}$ and $\mathrm{pH}$ changes from the photosynthetic and metabolic activities of algae.

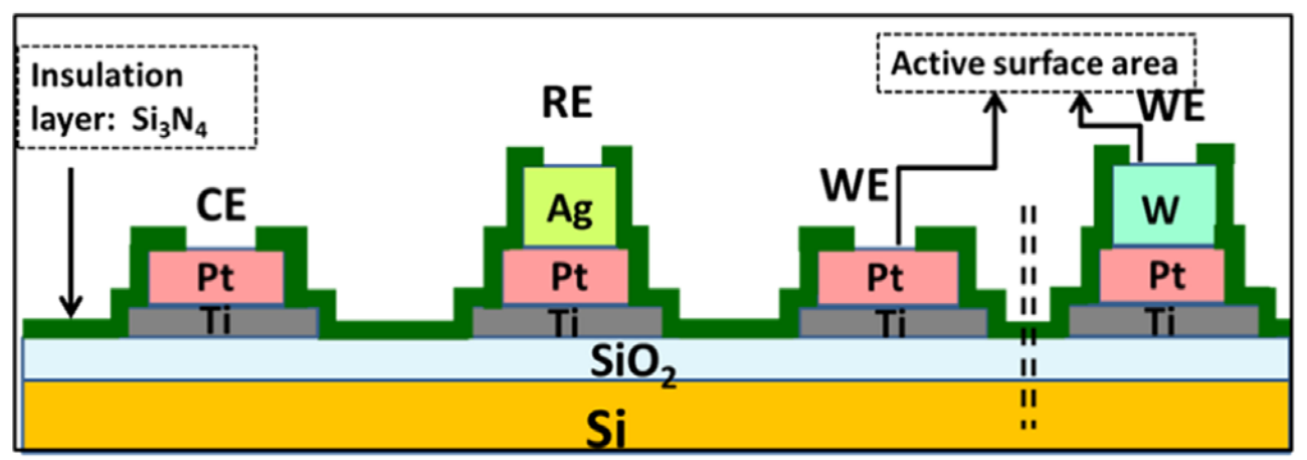

Figure 21. Schematic representation of the micro-fabricated electrochemical sensor. Reprinted from [140] with permission from Elsevier.

Chouteau et al. [141] described interdigitated conductimetric electrodes onto which the microalgae Chlorella vulgaris is immobilized. This microalgae contain alkaline phosphatase which locally produces phosphate ions, modifying the local ionic conductivity. Alkaline phosphatase is known to be inhibited 
by heavy metals such as $\mathrm{Cd}^{2+}$ and $\mathrm{Zn}^{2+}$, with a $\mathrm{LoD}$ of ca. $10 \mathrm{ppb}$ for a $30 \mathrm{~min}$ long exposure. A similar sensor was described later by the same research team [142] where the microalgae were immobilized on the interdigitated area through self-assembled monolayers (SAMs) of alkanethiol. Very recently, using similar interdigitated electrodes, Tekaya et al. [143] described a bi-enzymatic biosensor made by immobilizing Arthrospira platensis cells and using impedance spectroscopy to characterize cells' activity. Phosphatase and esterase activities were inhibited, respectively, by heavy metals such as $\mathrm{Cd}^{2+}$ and $\mathrm{Hg}^{2+}$, and by selected pesticides, with extremely low LoD of ca. $10^{-20} \mathrm{M}$. Complex matrixes such as a municipal wastewater were used to demonstrate its pertinence (Figure 22).
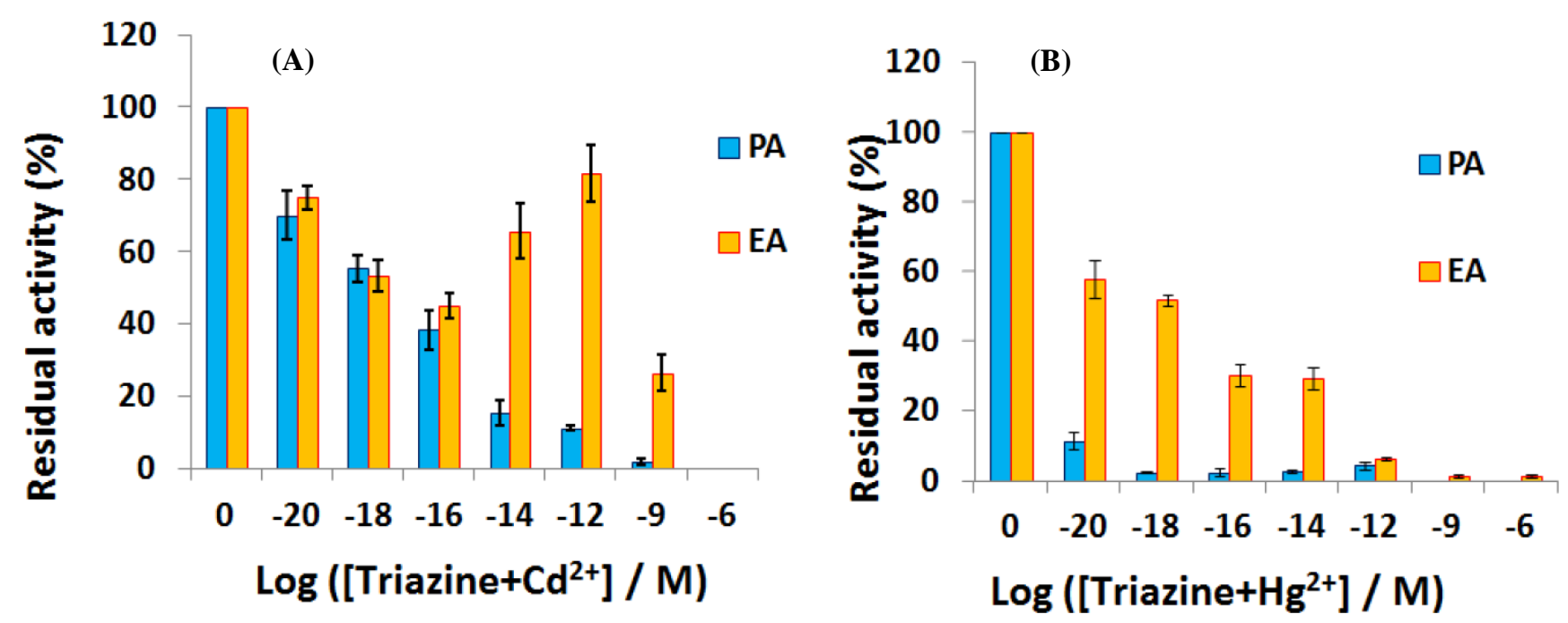

Figure 22. Residual activity of phosphatases and esterases enzymes after $12 \mathrm{~h}$ exposure to a couple of organic pollutant and heavy metal ion such as (A) (triazine $\left.+\mathrm{Cd}^{2+}\right)$ and $(\mathbf{B})$ (triazine $\left.+\mathrm{Hg}^{2+}\right)$. Reproduced from [143] with permissions.

\section{Conclusions and Perspectives}

There is an important bibliography concerning electrochemical detection of heavy metals, most of them based on stripping voltammetry, using various materials for modification of the electrodes. Some of these sensors are very sensitive, some are very selective and some are both sensitive and selective. However, none have replaced current standard analytical procedures. The main advantages and drawbacks of the major techniques reviewed in this manuscript are briefly summarized in Table 3 .

As described in Section 5.4, the use of living materials is the classical technique to detect pollutants, and biomaterials such as whole cells or enzymes are certainly the most promising sensing elements for interfacing with modern electronics. Electrochemical transistors are the most compatible with biointerfaces [144] because they are sensitive to both ions and electrons. For example, a conducting polymer-based transistor was very recently described for monitoring the activity of living epithelial cells, with a proof-of-concept for toxicology studies and diagnostic applications [145]. Another group described an organic electrochemical transistor (OECT) based on poly(3,4-ethylenedioxythiophene): poly(styrene sulfonic acid) (PEDOT:PSS) successfully used for the detection of marine diatoms (algae) directly in seawater. These living microalgae, when immobilized at the gate electrode, produce a gate offset voltage of several tens of $\mathrm{mV}$, which significantly shifts the transfer curves of the OECT to higher gate voltage. Such organic transistors are perfectly able to monitor the activity of these microalgae, 
known to be sensitive to heavy metals. They pave the way for biochemical sensing, particularly in marine environments [146]. Still, with the same kind of OECT, Kergoat et al. demonstrated the possibility to functionalize PEDOT:PSS with platinum NPs in order to complement the best sensitivity an enzymatic activity. They made the proof of concept with AChE for a completely different application, but as AChE is known to be particularly inhibited by HMs, this work also paves the way to analytical applications [147]. Lastly, even though they are not organic transistors, electrolyte-gated transistors (EGTs) based on ZnO thin film were used for physiological and environmental monitoring, with proof of concepts for enzymatic glucose sensing and also selective ion sensing [148].

Table 3. Main advantages and drawbacks of the major techniques reviewed in this manuscript.

\begin{tabular}{lll}
\hline \multicolumn{1}{c}{ Techniques } & \multicolumn{1}{c}{ Advantages } & \multicolumn{1}{c}{ Drawbacks } \\
\hline Metallic or carbon electrodes & Sub-ppb detection & Lack of specificity \\
& Easily miniaturisable & Lack of reproducibility \\
& On-field detection & Formation of intermetallic compounds \\
& & $\begin{array}{l}\text { Formation of biofilms and fouling } \\
\text { Chemically modified electrodes }\end{array}$ \\
with CPs & Sub-ppb detection & Sensibility \\
& Specificity & Stability \\
Electrodes modified with & Anti-fouling & Costs \\
biomolecules & Specificity & Long-term stability \\
& & Not yet available for on-field detection \\
\hline
\end{tabular}

Interfacing between electrodes and biomolecules is still a work in progress. To aid in this development, the user interface must progress as well. Very recently, a paper described a handheld device that couples an electrochemical sensor (illustrated for analysis of lead, cadmium, and zinc in water) with a mobile phone capable of supplying power and data transmission, for in-field environmental monitoring, even with a low level of technical expertise [149]. Clearly, there is plenty of room for smart bioelectrochemical sensing of HMs in the years to come.

\section{Acknowledgments}

The authors thank Bpifrance, grant n A1310024Q and Vietnam Nafosted, project code 104.03-2011.58, for funding.

\section{Conflicts of Interest}

The authors declare no conflict of interest.

\section{References}

1. Durkalec, M.; Szkoda, J.; Kolacz, R.; Opalinski, S.; Nawrocka, A.; Zmudzki, J. Bioaccumulation of lead, cadmium and mercury in roe deer and wild boars from areas with different levels of toxic metal pollution. Int. J. Environ. Res. 2015, 9, 205-212. 
2. Evans, E.H.; Day, J.A.; Palmer, C.D.; Price, W.J.; Smith, C.M.M.; Tyson, J.F. Atomic spectrometry update. Advances in atomic emission, absorption, and fluorescence spectrometry, and related techniques. J. Anal. At. Spectrom. 2005, 20, 562-590.

3. Montes-Bayon, M.; DeNicola, K.; Caruso, J.A. Liquid chromatography-inductively coupled plasma mass spectrometry. J. Chromatogr. A 2003, 1000, 457-476.

4. Zhang, Y.; Adeloju, S.B. Coupling of non-selective adsorption with selective elution for novel in-line separation and detection of cadmium by vapour generation atomic absorption spectrometry. Talanta 2015, 137, 148-155.

5. Harrington, C.F.; Clough, R.; Drennan-Harris, L.R.; Hill, S.J.; Tyson, J.F. Atomic spectrometry update. Elemental speciation. J. Anal. At. Spectrom. 2011, 26, 1561-1595.

6. Asher, S.A.; Sharma, A.C.; Goponenko, A.V.; Ward, M.M. Photonic crystal aqueous metal cation sensing materials. Anal. Chem. 2003, 75, 1676-1683.

7. Arunbabu, D.; Sannigrahi, A.; Jana, T. Photonic crystal hydrogel material for the sensing of toxic mercury ions $\left(\mathrm{Hg}^{2+}\right)$ in water. Soft Matter 2011, 7, 2592-2599.

8. Hong, W.; Li, W.; Hu, X.; Zhao, B.; Zhang, F.; Zhang, D. Highly sensitive colorimetric sensing for heavy metal ions by strong polyelectrolyte photonic hydrogels. J. Mater. Chem. 2011, 21, 17193-17201.

9. Cai, Z.; Zhang, J.T.; Xue, F.; Hong, Z.; Punihaole, D.; Asher, S.A. 2D Photonic Crystal Protein Hydrogel Coulometer for Sensing Serum Albumin Ligand Binding. Anal. Chem. 2014, 86, 4840-4847.

10. Hutton, E.A.; van Elteren, J.T.; Ogorevc, B.; Smyth, M.R. Validation of bismuth film electrode for determination of cobalt and cadmium in soil extracts using ICP-MS. Talanta 2004, 63, 849-855.

11. Chatzitheodorou, E.; Economou, A.; Voulgaropoulos, A. Trace determination of chromium by square-wave adsorptive stripping voltammetry on bismuth film electrodes. Electroanalysis 2004, $16,1745-1754$.

12. Kefala, G.; Economou, A.; Sofoniou, M. Determination of trace aluminium by adsorptive stripping voltammetry on a preplated bismuth-film electrode in the presence of cupferron. Talanta 2006, 68, 1013-1019.

13. Wang, H.; Yu, Z.; Wang, Z.; Hao, H.; Chen, Y.; Wan, P. Preparation of a preplated bismuth film on Pt electrode and its application for determination of trace aluminum(iii) by adsorptive stripping voltammetry. Electroanalysis 2011, 23, 1095-1099.

14. Adam, V.; Zehnalek, J.; Petrlova, J.; Potesil, D.; Sures, B.; Trnkova, L.; Kizek, R. Phytochelatin modified electrode surface as a sensitive heavy-metal ion biosensor. Sensors 2005, 5, 70-84.

15. Bonil, Y.; Brand, M.; Kirowa-Eisner, E. Determination of sub- $\mu \mathrm{g} \cdot \mathrm{L}^{-1}$ concentrations of copper by anodic stripping voltammetry at the gold electrode. Anal. Chim. Acta 1999, 387, 85-95.

16. Bonfil, Y.; Brand, M.; Kirowa-Eisner, E. Characteristics of subtractive anodic stripping voltammetry of $\mathrm{Pb}$ and $\mathrm{Cd}$ at silver and gold electrodes. Anal. Chim. Acta 2002, 464, 99-114.

17. Brand, M.; Eshkenazi, I.; Kirowa-Eisner, E. The Silver electrode in square-wave anodic stripping voltammetry. Determination of $\mathrm{Pb}^{2+}$ without removal of oxygen. Anal. Chem. 1997, 69, 4660-4664.

18. Kirowa-Eisner, E.; Brand, M.; Tzur, D. Determination of sub-nanomolar concentrations of lead by anodic-stripping voltammetry at the silver electrode. Anal. Chim. Acta 1999, 385, 325-335. 
19. Bonfil, Y.; Kirowa-Eisner, E. Determination of nanomolar concentrations of lead and cadmium by anodic-stripping voltammetry at the silver electrode. Anal. Chim. Acta 2002, 457, 285-296.

20. Simm, A.; Banks, C.; Compton, R.G. Sonoelectroanalytical detection of ultra-trace arsenic. Electroanalysis 2005, 17, 335-342.

21. Simm, A.; Banks, C.; Compton, R.G. The electrochemical detection of Arsenic(III) at a silver electrode. Electroanalysis 2005, 17, 1727-1733.

22. Rahman, M.; Okajima, T.; Ohsaka, T. Selective detection of As(III) at the Au(111)-like polycrystalline gold electrode. Anal. Chem. 2010, 82, 9169-9176.

23. Song, Y.; Swain, G. Total inorganic arsenic detection in real water samples using anodic stripping voltammetry and a gold-coated diamond thin-film electrode. Anal. Chim. Acta 2007, 593, 7-12.

24. Welsh, C.; Nekrassova, O.; Compton, R.G. Reduction of hexavalent chromium at solid electrodes in acidic media: Reaction mechanism and analytical applications. Talanta 2005, 65, 74-80.

25. Kachoosangi, R.T.; Compton, R.G. Voltammetric determination of Chromium(VI) using a gold film modified carbon composite electrode. Sens. Actuators. B 2013, 178, 555-562.

26. Dai, X.; Nekrassova, O.; Hyde, M.E.; Compton, R.G. Anodic stripping voltammetry of Arsenic(III) using gold nanoparticle-modified electrodes. Anal. Chem. 2004, 76, 5924-5929.

27. Jena, B.K.; Raj, C.R. Gold Nanoelectrode ensembles for the simultaneous electrochemical detection of ultratrace arsenic, mercury, and copper. Anal. Chem. 2008, 80, 4836-4844.

28. Jena, B.K.; Raj, C.R. Highly sensitive and selective electrochemical detection of sub-ppb level chromium (VI) using nano-sized gold particle. Talanta 2008, 76, 161-165.

29. Mardegan, A.; Scopece, P.; Lamberti, F.; Meneghetti, M.; Moretto, L.M.; Ugo, P. Electroanalysis of trace inorganic arsenic with gold nanoelectrode ensembles. Electroanalysis 2012, 24, 798-806.

30. Wang, J.; Lu, J.M.; Hocevar, S.B.; Farias, P.A.M.; Ogorevc, B. Bismuth-coated carbon electrodes for anodic stripping voltammetry. Anal. Chem. 2000, 72, 3218-3222.

31. Wang, J.; Lu, J.; Kirgöz, U.A.; Hocevar, S.B.; Ogorevc, B. Insights into the anodic stripping voltammetric behavior of bismuth film electrodes. Anal. Chim. Acta 2001, 434, 29-34.

32. Serrano, N.; Alberich, A.; Diaz-Cruz, J.M.; Arino, C.; Esteban, M. Coating methods, modifiers and applications of bismuth screen-printed electrodes. TrAC. Trends Anal. Chem. 2013, 46, $15-29$.

33. Wang, J.; Lu, J.M.; Hocevar, S.B.; Ogorevc, B. Bismuth-coated screen-printed electrodes for stripping voltammetric measurements of trace lead. Electroanalysis 2001, 13, 13-16.

34. Salles, M.O.; de Suza, A.P.R.; Naozuka, J.; de Oliveira, P.V.; Bertotti, M. Bismuth modified gold microelectrode for $\mathrm{Pb}$ (II) determination in wine using alkaline medium. Electroanalysis 2009, 21, 1439-1442.

35. Demetriadis, T.; Economou, A.; Voulgaropoulos, A. A study of pencil-lead bismuth-film electrodes for the determination of trace metals by anodic stripping voltammetry. Anal. Chim. Acta. 2004, 519, 167-172.

36. Kadara, R.O.; Tothill, I.E. Stripping chronopotentiometric measurements of lead(II) and cadmium(II) in soils extracts and wastewaters using a bismuth film screen-printed electrode assembly. Anal. Bioanal. Chem. 2004, 378, 770-775.

37. Economou, A. Bismuth-film electrodes: Recent developments and potentialities for electroanalysis. TrAC, Trends Anal. Chem. 2005, 24, 334-340. 
38. Nunes, L.; Faria, R. The Influence of the Electrodeposition Conditions on the Electroanalytical Performance of the Bismuth Film Electrode for Lead Determination. Electroanalysis 2008, 20, 2259-2263.

39. Kang, W.; Pei, X.; Yue, W.; Bange, A.; Heineman, W.; Papautsky, I. Lab-on-a-Chip Sensor with Evaporated Bismuth Film Electrode for Anodic Stripping Voltammetry of Zinc. Electroanalysis 2013, 25, 2586-2594.

40. Kokkinos, C.; Economou, A.; Raptis, I.; Efstathiou, C.; Speliotis, T. Novel disposable bismuth-sputtered electrodes for the determination of trace metals by stripping voltammetry. Electrochem. Commun. 2007, 9, 2795-2800.

41. Kokkinos, C.; Economou, A.; Raptis, I.; Speliotis, T. Disposable lithographically fabricated bismuth microelectrode arrays for stripping voltammetric detection of trace metals. Electrochem. Commun. 2011, 13, 391-395.

42. Kokkinos, C.; Economou, A.; Raptis, I.; Speliotis, T. Disposable microfabricated bismuth microelectrode arrays for trace metal analysis by stripping voltammetry. Procedia Engineering 2011, 25, 880-883.

43. Kokkinos, C.; Economou, A.; Raptis, I. Microfabricated disposable lab-on-a-chip sensors with integrated bismuth microelectrode arrays for voltammetric determination of trace metals. Anal. Chim. Acta 2012, 710, 1-8.

44. Hocevar, S.B.; Svancara, I.; Ogorvc, B.; Vytras, K. Antimony Film Electrode for Electrochemical Stripping Analysis. Anal. Chem. 2007, 79, 8639-8643.

45. Uhl, A.; Kestranek, W. The electrometric titration of acids and bases with the antimony indicator electrodes. Monatsh. Chem. 1923, 44, 29-34.

46. Sebez, B.; Ogorevc, B.; Hocevar, S.B.; Veber, M. Functioning of antimony film electrode in acid media under cyclic and anodic stripping voltammetry conditions. Anal. Chim. Acta 2013, 785, 43-49.

47. Kokkinos, C.; Economou, A.; Raptis, I.; Speliotis, T. Novel disposable microfabricated antimony-film electrodes for adsorptive stripping analysis of trace Ni(II). Electrochem. Commun. 2009, 11, 250-253.

48. Sopha, H.; Jovanovski, V.; Hocevar, S.B.; Ogorevc, B. In-situ plated antimony film electrode for adsorptive cathodic stripping voltammetric measurement of trace nickel. Electrochem. Commun. 2012, 20, 23-25.

49. Zhu, P.L.; Zhu, J.Z.; Yang, S.Z.; Zhang, X.K.; Zhang, G.X. Electrochemical characterization of boron-doped polycrystalline diamond thin-film electrodes. Fresenius J. Anal. Chem. 1995, 353, 171-173.

50. McGaw, A.E.; Swain, M.G. A comparison of boron-doped diamond thin-film and Hg-coated glassy carbon electrodes for anodic stripping voltammetric determination of heavy metal ions in aqueous media. Anal. Chim. Acta 2006, 575, 180-189.

51. Manivannan, A.; Ramakrishnan, L.; Seehra, M.S.; Granite, E.; Butler, J.E.; Tryk, D.A.; Fujishima, A. Mercury detection at boron doped diamond electrodes using a rotating disk technique. J. Electroanal. Chem. 2005, 577, 287-293. 
52. Dragoe, D.; Sparatu, N.; Kawasaki, R.; Manivannan, A.; Sparatu, T.; Tryk, D.A.; Fujishima, A. Detection of trace levels of $\mathrm{Pb}^{2+}$ in tap water at boron-doped diamond electrodes with anodic stripping voltammetry. Electrochim. Acta 2006, 51, 2437-2441.

53. Chooto, P.; Wararatananurak, P.; Innuphat, C. Determination of trace levels of $\mathrm{Pb}(\mathrm{II})$ in tap water by anodic stripping voltammetry with boron-doped diamond electrode. ScienceAsia 2010, 36, $150-156$.

54. Saterlay, A.J.; Agra-Gutierrez, C.; Taylor, M.P.; Marken, F.; Compton, R.G. Sono-cathodic stripping voltammetry of lead at a polished boron-doped diamond electrode: Application to the determination of lead in river sediment. Electroanalysis 1999, 11, 1083-1088.

55. Banks, C.E.; Hyde, M.E.; Tomcik, P.; Jacobs, R.; Compton, R.G. Cadmium detection via boron-doped diamond electrodes: Surfactant inhibited stripping voltammetry. Talanta 2004, 62, 279-286.

56. Saterlay, A.J.; Foord, J.S.; Compton, R.G. Sono-cathodic stripping voltammetry of manganese at a polished boron-doped diamond electrode: Application to the determination of manganese in instant tea. Analyst 1999, 124, 1791-1796.

57. Saterlay, A.J.; Marken, F.; Foord, J.S.; Compton, R.G. Sonoelectrochemical investigation of silver analysis at a highly boron-doped diamond electrode. Talanta 2000, 53, 403-415.

58. Sonthalia, P.; McGaw, A.E.; Show, Y.; Swain, M.G. Metal ion analysis in contaminated water samples using anodic stripping voltammetry and a nanocrystalline diamond thin-film electrode. Anal. Chim. Acta 2004, 522, 35-44.

59. Tall, O.E.; Jaffrezic-Renault, N.; Sigaud, M.; Vittori, O. Anodic stripping voltammetry of heavy metals at nanocrystalline boron-doped diamond electrode. Electroanalysis 2007, 19, 1152-1159.

60. Yoon, J.-H.; Yang, J.E.; Kim, J.P.; Bae, J.S.; Shim, Y.-B.; Won, M.-S. Simultaneous detection of $\mathrm{Cd}$ (II), $\mathrm{Pb}$ (II), $\mathrm{Cu}$ (II), and $\mathrm{Hg}$ (II) ions in dye waste water using a boron doped diamond electrode with DPASV. Bull. Korean Chem. Soc. 2010, 31, 140-145.

61. Sbartai, A.; Namour, P.; Errachid, A.; Krejci, J.; Sejnohova, R.; Renaud, L.; Larbi, H.M.; Loir, A.-S.; Garrelie, F.; Donnet, C.; et al. Electrochemical boron-doped diamond film microcells micromachined with femtosecond laser: Application to the determination of water framework directive metals. Anal. Chem. 2012, 84, 4805-4811.

62. Hutton, L.; Newton, M.E.; Unwin, P.; MacPherson, J.V. Factors controlling stripping voltammetry of lead at polycrystalline boron doped diamond electrodes: New insights from high-resolution microscopy. Anal. Chem.2011, 83, 735-745.

63. Prado, C.; Wilkins, S.J.; Marken, F.; Compton, R.G. Simultaneous electrochemical detection and determination of lead and copper at boron-doped diamond film electrodes. Electroanalysis 2002, 14, 262-272.

64. Manivannan, A.; Kawasaki, R.; Tryk, D.A.; Fujishima, A. Interaction of $\mathrm{Pb}$ and $\mathrm{Cd}$ during anodic stripping voltammetric analysis at boron-doped diamond electrodes. Electrochim. Acta 2004, 49, 3313-3318.

65. Robertson, J. Diamond-like amorphous carbon. Mat. Sci. Eng. 2002, R37, 129-281.

66. Zeng, A.; Liu, E.; Tan, S.; Zhang, S.; Gao, J. Stripping voltammetric analysis of heavy metals at nitrogen doped diamond-like carbon film electrodes. Electroanalysis 2002, 14, 1294-1298. 
67. Khun, N.W.; Liu, E. Linear sweep anodic stripping voltammetry of heavy metals from nitrogen doped tetrahedral amorphous carbon thin films. Electrochim. Acta 2009, 54, 2890-2898.

68. Liu, L.X.; Liu, E. Nitrogenated diamond-like carbon films for metal tracing. Surf. Coat. Technol. 2005, 198, 189-193.

69. Khadro, B.; Sikora, A.; Loir, A.; Errachid, A.; Garrelie, F.; Donnet, C.; Jaffrezic-Renault, N. Electrochemical performances of $\mathrm{B}$ doped and undoped diamond-like carbon (DLC) films deposited by femtosecond pulsed laser ablation for heavy metal detection using square wave anodic stripping voltammetric (SWASV) technique. Sens. Actuators. B 2011, 155, 120-125.

70. Pickup, N.L.; Shapiro, J.S.; Wong, D.K.Y. Extraction of silver by polypyrrole films upon a base \pm acid treatment. Anal. Chim. Acta 1998, 364, 41-51.

71. Song, F.Y.; Shiu, K.K. Preconcentration and electroanalysis of silver species at polypyrrole film modified glassy carbon electrodes. J. Electroanal. Chem. 2001, 498, 161-170.

72. Zejli, H.; Izaoumen, N.; Bouchta, D.; El Kaoutit, M.; Temsamani, K.R. Electrochemically aided solid phase micro-extraction of mercury(II) at poly(3-methylthiophene) modified gold electrode. Anal. Lett. 2004, 37, 1737-1754.

73. Zejli, H.; Sharrock, P.; Hidalgo-Hidalgo de Cisneros, J.L.; Naranjo-Rodriguez, I.; Temsamani, K.R. Voltammetric determination of trace mercury at a sonogel-carbon electrode modified with poly-3-methylthiophene. Talanta 2006, 68, 79-85.

74. Yasri, N.G.; Halabi, A.J.; Istamboulie, G.; Noguer, T. Chronoamperometric determination of lead ions using PEDOT:PSS modified carbon electrodes. Talanta 2011, 85, 2528-2533.

75. Liu, Q.; Wang, F.; Qiao, Y.; Zhang, S.; Ye, B. Polyaniline Langmuir-Blodgett film modified glassy carbon electrode as a voltammetric sensor for determination of $\mathrm{Ag}^{+}$ions. Electrochim. Acta 2010, $55,1795-1800$.

76. Wang, Z.; Liu, E.; Zhao, X. Glassy carbon electrode modified by conductive polyaniline coating for determination of trace lead and cadmium ions in acetate buffer solution. Thin Solid Films 2011, 519, 5285-5289.

77. Pham, M.C.; Oulahyane, M.; Mostefai, M.; Chehimi, M.M. Multiple internal reflection FT-IR spectroscopy (MIRFTIRS) study of the electrochemical synthesis and the redox process of poly(1,5-diaminonaphthalene). Synth. Met. 1998, 93, 89-96.

78. Kilian, K. Affinity of some metal ions towards1,8-diaminonaphthalene conductive polymer. React. Funct. Polym. 2008, 68, 974-980.

79. Pałys, B.J.; Skompska, M.; Jackowska, K. Sensitivity of poly 1,8-diaminonaphthalene to heavy metal ions-electrochemical and vibrational spectra studies. J. Electroanal. Chem. 1997, 433, $41-48$.

80. Li, X.G.; Huang, M.R.; Li, S.X. Facile synthesis of poly(1,8-diaminonaphthalene) microparticles with a very high silver-ion adsorbability by a chemical oxidative polymerization. Acta Mater. 2004, 52, 5363-5374.

81. Won, M.S.; Yoon, J.H.; Shim, Y.B. Determination of selenium with a poly(1,8-diaminonaphthalene)modified electrode. Electroanalysis 2005, 17, 1952-1958.

82. Majid, S.; el Rhazi, M.; Amine, A.; Curulli, A.; Palleschi, G. Carbon paste electrode bulk-modified with the conducting polymer poly(1,8-diaminonaphthalene): Application to lead determination. Microchim. Acta 2003, 143, 195-204. 
83. Zanganeh, A.R.; Amini, M.K. A potentiometric and voltammetric sensor based on polypyrrole film with electrochemically induced recognition sites for detection of silver ion. Electrochim. Acta 2007, $52,3822-3830$.

84. Lisak, G.; Wagner, M.; Kvarnstrom, C.; Bobacka, J.; Ivaska, A.; Lewenstam, A. Electrochemical behaviour of poly(benzopyrene) films doped with Eriochrome black $\mathrm{T}$ as $\mathrm{Pb}^{2+}$-sensitive sensors. Electroanalysis 2010, 22, 2794-2800.

85. Yoo, K.S.; Woo, S.B.; Jyoung, J.Y. Trace mercury determination by differential pulse anodic stripping voltammetry using polythiophene-quinoline/glassy carbon modified electrode. Bull. Korean Chem. Soc. 2003, 24, 27-31.

86. Somerset, V.; Leaner, J.; Mason, R.; Iwuoha, E.; Morrin, A. Determination of inorganic mercury using a polyaniline and polyaniline-methylene blue coated screen-printed carbon electrode. Int. J. Environ. Anal. Chem. 2010, 90, 671-685.

87. Somerset, V.; Leaner, J.; Mason, R.; Iwuoha, E.; Morrin, A. Development and application of a poly(2,2'-dithiodianiline) (PDTDA)-coated screen-printed carbon electrode in inorganic mercury determination. Electrochim. Acta 2010, 55, 4240-4246.

88. Philips, M.F.; Gopalan, A.L.; Lee, K.P. Development of a novel cyano group containing electrochemically deposited polymer film for ultrasensitive simultaneous detection of trace level cadmium and lead. J. Hazard. Mater. 2012, 237-238, 46-54.

89. Kumar, P.; Joseph, A.; Ramamurthy, P.C.; Subramanian, S. Lead ion sensor with electrodes modified by imidazole-functionalized polyaniline. Microchim. Acta 2012, 177, 317-323.

90. Chen, L.; Li, Z.; Meng, Y.; Zhang, P.; Su, Z.; Liu, Y.; Huang, Y.; Zhou, Y.; Xie, Q.; Yau, S. Sensitive square wave anodic stripping voltammetric determination of $\mathrm{Cd}^{2+}$ and $\mathrm{Pb}^{2+}$ ions at $\mathrm{Bi} /$ Nafion/overoxidized 2-mercaptoethanesulfonate-tethered polypyrrole/glassy carbon electrode. Sens. Actuators. B 2014, 191, 94-101.

91. Fu, X.C.; Chen, X.; Guo, Z.; Xie, C.G.; Kong, L.T.; Liu, J.H.; Huang, X.J. Stripping voltammetric detection of mercury(II) based on a surface ion imprinting strategy in electropolymerized microporous poly(2-mercaptobenzothiazole) films modified glassy carbon electrode. Anal. Chim. Acta 2011, 685, 21-28.

92. Rahman, M.; Won, M.S.; Shim, Y.B. Characterization of an EDTA bonded conducting polymer modified electrode: Its application for the simultaneous determination of heavy metal ions. Anal. Chem. 2003, 75, 1123-1129.

93. Heitzmann, M.; Bucher, C.; Moutet, J.C.; Pereira, E.; Rivas, B.L.; Royal, G.; Saint-Aman, E. Complexation of poly(pyrrole-EDTA like) film modified electrodes: Application to metal cations electroanalysis. Electrochim. Acta 2007, 52, 3082-3087.

94. Cortina-Puig, M.; Munoz-Berbel, X.; del Valle, M.; Munoz, F.J.; Alonso-Lomillo, M.A. Characterization of an ion-selective polypyrrole coating and application to the joint determination of potassium, sodium and ammonium by electrochemical, impedance spectroscopy and partial least squares method. Anal. Chim. Acta 2007, 597, 231-237.

95. Muthukumar, C.; Kesarkar, S.D.; Srivastava, D.N. Conductometric mercury [II] sensor based on polyaniline-cryptand-222 hybrid. J. Electroanal. Chem. 2007, 602, 172-180. 
96. Evtugyn, G.A.; Stoikov, I.I.; Beljyakova, S.V.; Shamagsumova, R.V.; Stoikova, E.E.; Zhukov, A.Y.; Antipin, I.S.; Budnikov, H.C. Ag selective electrode based on glassy carbon electrode covered with polyaniline and thiacalix[4]arene as neutral carrier. Talanta 2007, 71, 1720-1727.

97. Wang, Z.; Liu, E.; Gu, D.; Wang, Y. Glassy carbon electrode coated with polyaniline-functionalized carbon nanotubes for detection of trace lead in acetate solution. Thin Solid Films 2011, 519, 5280-5284.

98. Salmanipour, A.; Taher, M.A. An electrochemical sensor for stripping analysis of $\mathrm{Pb}$ (II) based on multiwalled carbon nanotube functionalized with 5-Br-PADAP. J. Solid State Electrochem. 2011, 15, 2695-2702.

99. Nguyen, T.D.; Tran, L.D.; Nguyen, H.L.; Nguyen, B.H.; Nguyen, V.H. Modified interdigitated arrays by novel poly(1,8-diaminonaphthalene)/carbon nanotubes composite for selective detection of mercury(II). Talanta 2011, 85, 2445-2450.

100. Nguyen, T.D.; Nguyen, T.M.; Ho, T.G.; Nguyen, N.T.; Reisberg, S.; Piro, B.; Pham, M.C. Design of interpenetrated network MWCNT/Poly(1,5-DAN) on interdigital electrode: Towards $\mathrm{NO}_{2}$ gas sensing. Talanta 2013, 115, 713-717.

101. Vu, H.D.; Nguyen, L.H.; Nguyen, T.D.; Nguyen, H.B.; Nguyen, T.L.; Tran, D.L. Anodic stripping voltammetric determination of $\mathrm{Cd}^{2+}$ and $\mathrm{Pb}^{2+}$ using interpenetrated MWCNT/P1,5-DAN as an enhanced sensing interface. Ionics 2015, 21, 571-578.

102. Turdean, G.L. Design and development of biosensors for the detection of heavy metal toxicity. Int. J. Electrochem. 2011, 2011, doi:10.4061/2011/343125.

103. Kukla, A.L.; Kanjuk, N.I.; Starodub, N.F.; Shirshov, Y.M. Multienzyme electrochemical sensor array for determination of heavy metal ions. Sens. Actuators. B 1999, 57, 213-218.

104. Bagal-Kestwal, D.; Karve, M.S.; Kakade, B.; Pillai, V.K. Invertase inhibition based electrochemical sensor for the detection of heavy metal ions in aqueous system: Application of ultra-microelectrode to enhance sucrose biosensor's sensitivity. Biosens. Bioelectron. 2008, 24, 657-664.

105. Ono, A.; Togashi, H. Highly selective oligonucleotide-based sensor for mercury(II) in aqueous solutions. Angew. Chem. Int. Ed. 2004, 43, 4300-4302.

106. Bu, N.N.; Tang, C.X.; He, X.W.; Yin, X.B. Tetrahedron-structured DNA and functional oligonucleotide for construction of an electrochemical DNA-based biosensor. Chem. Commun. 2011, 47, 7689-7691.

107. Mor-Piperberg, G.; Tel-Vered, R.; Elbaz, J.; Willner, I. Nanoengineered electrically contacted enzymes on DNA scaffolds: Functional assemblies for the selective analysis of $\mathrm{Hg}^{2+}$ ions. J. Am. Chem. Soc. 2010, 132, 6878-6879.

108. Shi, L.; Shu, Z.; Liu, Y.; Jin, W.; Chen, X. An ultrasensitive electrochemical sensing platform for $\mathrm{Hg}^{2+}$ based on a density controllable metal-organic hybrid microarray. Biosens. Bioelectron. 2014, $54,165-170$.

109. Tang, X.; Liu, H.; Zou, B.; Tian, D.; Huang, H. A fishnet electrochemical $\mathrm{Hg}^{2+}$ sensing strategy based on gold nanoparticle-bioconjugate andthymine- $\mathrm{Hg}^{2+}$-thymine coordination chemistry. Analyst 2012, 137, 309-311.

110. Liu, S.; Nie, H.; Jiang, J.; Shen, G.; Yu, R. Electrochemical sensor for mercury(II) based on conformational switch mediated by interstrand cooperative coordination. Anal. Chem. 2009, 81, 5724-5730. 
111. Han, D.; Kim, Y.R.; Oh, J.W.; Kim, T.H.; Mahajan, R.K.; Kim, J.S.; Kim, H. A regenerative electrochemical sensor based on oligonucleotide for the selective determination of mercury(II). Analyst 2009, 134, 1857-1862.

112. Zhuang, J.; Fu, L.; Tang, D.; Xu, M.; Chen, G.; Yang, H. Target-induced structure-switching DNA hairpins for sensitive electrochemical monitoring of mercury (II). Biosens. Bioelectron. 2013, 39, 315-319.

113. Wu, D.; Zhang, Q.; Chu, X.; Wang, H.; Shen, G.; Yu, R. Ultrasensitive electrochemical sensor for mercury (II) based on target-induced structure-switching DNA. Biosens. Bioelectron. 2010, 25, 1025-1031.

114. Breaker, R.; Joyce, G. A DNA enzyme that cleaves RNA. Chem. Biol. 1994, 1, 223-229.

115. Chen, X.; Tian, R.; Zhang, Q.; Yao, C. Target-induced electronic switch for ultrasensitive detection of $\mathrm{Pb}^{2+}$ based on three dimensionally ordered macroporous Au-Pd bimetallic. Biosens. Biolectron. 2014, 53, 90-98.

116. Shen, L.; Chen, Z.; Li, Y.; He, S.; Xie, S.; Xu, X.; Liang, Z.; Meng, X.; Li, Q.; Zhu, Z. Electrochemical DNAzyme sensor for lead based on amplification of DNA-Au bio-bar codes. Anal. Chem. 2008, 80, 6323-6328.

117. Tang, S.; Tong, P.; Li, H.; Tang, J.; Zhang, L. Ultrasensitive electrochemical detection of $\mathrm{Pb}^{2+}$ based on rolling circle amplification and quantum dots tagging. Biosens. Bioelectron. 2013, 42, 608-611.

118. Ocaña, C.; Malashikhina, N.; del Valle, M.; Pavlov, V. Label-free selective impedimetric detection of $\mathrm{Cu}^{2+}$ ions using catalytic DNA. Analyst 2013, 138, 1995-1999.

119. Xiao, Y.; Rowe, A.A.; Plaxco, K.W. Electrochemical detection of parts-per-billion lead via an electrode-bound DNAzyme assembly. J. Am. Chem. Soc. 2007, 129, 262-263.

120. Lin, Z.; Chen, Y.; Li, X.; Fang, W. $\mathrm{Pb}^{2+}$ induced DNA conformational switch from hairpin to G-quadruplex: Electrochemical detection of $\mathrm{Pb}^{2+}$. Analyst 2011, 136, 2367-2372.

121. Li, F.; Feng, Y.; Zhao, C.; Tang, B. Crystal violet as a G-quadruplex-selective probe for sensitive amperometric sensing of lead. Chem. Commun. 2011, 47, 11909-11911.

122. Jarczewska, M.; Kierzkowska, E.; Ziółkowski, R.; Górski, L.; Malinowska, E. Electrochemical oligonucleotide-based biosensor for the determination of lead ion. Bioelectrochem. 2015, 101, 35-41.

123. Lian, Y.; Yuan, M.; Zhao, H. DNA Wrapped Metallic Single-walled Carbon Nanotube Sensor for $\mathrm{Pb}(\mathrm{II})$ Detection. Fuller. Nanotub. Carbon Nanostruct. 2014, 22, 510-518.

124. Chow, E.; Gooding, J.J. Peptide modified electrodes as electrochemical metal ion sensors. Electroanalysis 2006, 18, 1437-1448.

125. Viguier, B.; Zór, K.; Kasotakis, E.; Mitraki, A.; Clausen, C.H.; Svendsen, W.E.; Castillo-León, J. Development of an electrochemical metal-ion biosensor using self-assembled peptide nanofibrils. ACS Appl. Mater. Interfaces 2011, 3, 1594-1600.

126. Su, W.; Cho, M.; Nam, J.D.; Choe, W.S.; Lee, Y. Highly sensitive electrochemical lead ion sensor harnessing peptide probe molecules on porous gold electrodes. Biosens. Bioelectron. 2013, 48, 263-269.

127. Serrano, N.; Prieto-Simón, B.; Cetó, X.; del Valle, M. Array of peptide-modified electrodes for the simultaneous determination of $\mathrm{Pb}(\mathrm{II}), \mathrm{Cd}(\mathrm{II})$ and $\mathrm{Zn}(\mathrm{II})$. Talanta 2014, 125, 159-166. 
128. Daunert, S.; Barrett, G.; Feliciano, J.S.; Shetty, R.S.; Shrestha, S.; Smith-Spencer, W. Genetically engineered whole-cell sensing systems: Coupling biological recognition with reporter genes. Chem. Rev. 2000, 100, 2705-2738.

129. Hernández, C.A.; Osma, J.F. Whole cell biosensors. In Biosensors: Recent Advances and Mathematical Challenges; Osma, J.F., Stoytcheva, M., Eds.; Omnia Science: Terrassa, Spain, 2014; pp. 51-96.

130. Cheng, W.; Ding, L.; Lei, J.; Ding, S.; Ju, H. Effective cell capture with tetrapeptide-functionalized carbon nanotubes and dual signal amplification for cytosensing and evaluation of cell surface carbohydrate. Anal. Chem. 2008, 280, 3867-3872.

131. Ben-Yoav, H.; Almog, R.O.; Sverdlov, Y.; Sternheim, M.; Belkin, S.; Freeman, A.; Shacham-Diamand, Y. Modified working electrodes for electrochemical whole cell microchips. Electrochim. Acta 2012, 82, 109-114.

132. Wang, J.; Wu, C.; Hu, N.; Zhou, J.; Du, L.; Wang, P. Microfabricated electrochemical cell-based biosensors for analysis of living cells in vitro. Biosensors 2012, 2, 127-170.

133. Whole Cell Sensing Systems I, Reporter Cells and Devices, and Whole Cell Sensing System II, Applications. Series: Advances in Biochemical Engineering/Biotechnology; Belkin, S., Gu, M.B., Eds.; Springer: Vienna, Austria, 2010.

134. Adam, V.; Chudobova, D.; Tmejova, K.; Cihalova, K.; Krizkova, S.; Guran, R.; Kominkova, M.; Zurek, M.; Kremplova, M.; Jimenez, A.M.; et al. An effect of cadmium and lead ions on Escherichia coli with the cloned gene for metallothionein (MT-3) revealed by electrochemistry. Electrochim. Acta 2014, 140, 11-19.

135. Zhu, X.; Qin, H.; Liu, J.G.; Zhang, Z.; Lu, Y.; Yuan, X.; Wu, D. A novel electrochemical method to evaluate the cytotoxicity of heavy metals. J. Hazard. Mater. 2014, 271, 210-219.

136. Liu, Q.; Cai, H.; Xu, Y.; Xiao, L.; Yang, M.; Wang, P. Detection of heavy metal toxicity using cardiac cell-based biosensor. Biosens. Bioelectron. 2007, 22, 3224-3229.

137. Hafeman, D.G.; Parce, J.W.; McConnell, H.M. Light addressable potentiometric sensor for biochemical systems. Science 1988, 240, 1182-1185.

138. Ismail, A.B.; Yoshinobu, T.; Iwasaki, H.; Sugihara, H.; Yukimasa, T.; Hirata, L.; Iwata, H. Investigation on light-addressable potentiometric sensor as a possible cell-semiconductor hybrid. Biosens. Bioelectron. 2003, 18, 1509-1514.

139. Brayner, R.; Couté, A.; Livage, J.; Perrette, C.; Sicard, C. Micro-algal biosensors. Anal. Bioanal. Chem. 2011, 401, 581-597.

140. Tsopela, A.; Lale, A.; Vanhove, E.; Reynes, O.; Séguy, I.; Temple-Boyer, P.; Juneau, P.; Izquierdo, R.; Launay, J. Integrated electrochemical biosensor based on algal metabolism for water toxicity analysis. Biosens. Bioelectron. 2014, 61, 290-297.

141. Chouteau, C.; Dzyadevych, S.; Durrieu, C.; Chovelon, J.M. A bi-enzymatic whole cell conductometric biosensor for heavy metal ions and pesticides detection in water samples. Biosens. Bioelectron. 2005, 21, 273-281.

142. Guedri, H.; Durrieu, C. A self-assembled monolayers based conductometric algal whole cell biosensor for water monitoring. Microchim. Acta 2008, 163, 179-184. 
143. Tekaya, N.; Saiapina, O.; Ouada, H.B.; Lagarde, F.; Namour, P.; Ouada, H.B.; Jaffrezic-Renault, N. Bi-Enzymatic conductometric biosensor for detection of heavy metal ions and pesticides in water samples based on enzymatic inhibition in arthrospira platensis. J. Environ. Protect. 2014, 5, 441-453.

144. Higgins, S.; Hodgkiss, J.; Plank, N.; Torsi, L.; Cowper, P.; Malliaras, G.; Braeken, Y.; Laurand, N.; Samuel, I.; Pomorska, A.; et al. Organic bioelectronics: General discussion. Faraday Discuss. 2014, 174, 413-428.

145. Ramuz, M.; Hama, A.; Huerta, M.; Rivnay, J.; Leleux, P.; Owens, R.M. Combined optical and electronic sensing of epithelial cells using planar organic transistors. Adv. Mater. 2014, 26, 7083-7090.

146. Liao, J.; Lin, S.; Liu, K.; Yang, Y.; Zhang, R.; Du, W.; Li, X. Organic electrochemical transistor based biosensor for detecting marine diatoms in seawater medium. Sens. Actuators. B 2014, 203, 677-682.

147. Kergoat, L.; Piro, B.; Simon, D.T.; Pham, M.C.; Noël, V.; Berggren, M. Detection of glutamate and acetylcholine with organic electrochemical transistors based on conducting polymer/platinum nanoparticle composites. Adv. Mater. 2014, 26, 5658-5664.

148. Bandiello, E.; Sessolo, M.; Bolink, H.J. Aqueous electrolyte-gated $\mathrm{ZnO}$ transistors for environmental and biological sensing. J. Mater. Chem. C. 2014, 2, 10277-10281.

149. Nemiroski, A.; Christodouleas, D.C.; Hennek, J.W.; Kumar, A.A.; Maxwell, E.J.; Fernández-Abedul, M.T.; Whitesides, G.M. Universal mobile electrochemical detector designed for use in resource-limited applications. PNAS 2014, 111, 11984-11989.

(C) 2015 by the authors; licensee MDPI, Basel, Switzerland. This article is an open access article distributed under the terms and conditions of the Creative Commons Attribution license (http://creativecommons.org/licenses/by/4.0/). 